\title{
Comprehensive airborne characterization of aerosol from a major bovine source
}

\author{
A. Sorooshian ${ }^{1, *}$, S. M. Murphy ${ }^{1}$, S. Hersey ${ }^{1}$, H. Gates ${ }^{1}$, L. T. Padro ${ }^{2}$, A. Nenes ${ }^{2,3}$, F. J. Brechtel ${ }^{1,4}$, H. Jonsson ${ }^{5}$, \\ R. C. Flagan ${ }^{1}$, and J. H. Seinfeld ${ }^{1}$ \\ ${ }^{1}$ Departments of Environmental Science and Engineering and Chemical Engineering, California Institute of Technology, \\ Pasadena, CA, USA \\ ${ }^{2}$ School of Chemical and Biomolecular Engineering, Georgia Institute of Technology, Atlanta, GA, USA \\ ${ }^{3}$ School of Earth and Atmospheric Sciences, Georgia Institute of Technology, Atlanta, GA, USA \\ ${ }^{4}$ Brechtel Manufacturing Inc., Hayward, CA, USA \\ ${ }^{5}$ Center for Interdisciplinary Remotely-Piloted Aircraft Studies, Naval Postgraduate School, Monterey, CA, USA \\ *now at: Cooperative Inst. for Research in the Atmosphere (CIRA), Colorado State University, Fort Collins, CO, USA
}

Received: 23 April 2008 - Published in Atmos. Chem. Phys. Discuss.: 3 June 2008

Revised: 12 August 2008 - Accepted: 15 August 2008 - Published: 12 September 2008

\begin{abstract}
We report an extensive airborne characterization of aerosol downwind of a massive bovine source in the San Joaquin Valley (California) on two flights during July 2007. The Center for Interdisciplinary Remotely-Piloted Aircraft Studies (CIRPAS) Twin Otter probed chemical composition, particle size distribution, mixing state, sub- and supersaturated water uptake behavior, light scattering properties, and the interrelationship between these parameters and meteorology. Total $\mathrm{PM}_{1.0}$ levels and concentrations of organics, nitrate, and ammonium were enhanced in the plume from the source as compared to the background aerosol. Organics dominated the plume aerosol mass $(\sim 56-64 \%)$, followed either by sulfate or nitrate, and then ammonium. Particulate amines were detected in the plume aerosol by a particleinto-liquid sampler (PILS) and via mass spectral markers in the Aerodyne C-ToF-AMS. Amines were found to be a significant atmospheric base even in the presence of ammonia; particulate amine concentrations are estimated as at least 14$23 \%$ of that of ammonium in the plume. Enhanced sub- and supersaturated water uptake and reduced refractive indices were coincident with lower organic mass fractions, higher nitrate mass fractions, and the detection of amines. The likelihood of suppressed droplet growth owing to kinetic limitations from hydrophobic organic material is explored. After removing effects associated with size distribution and mixing state, the normalized activated fraction of cloud condensation nuclei $(\mathrm{CCN})$ increased as a function of the subsaturated
\end{abstract}

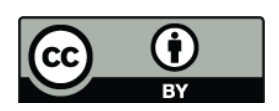

Correspondence to: J. H. Seinfeld (seinfeld@caltech.edu) hygroscopic growth factor, with the highest activated fractions being consistent with relatively lower organic mass fractions and higher nitrate mass fractions. Subsaturated hygroscopic growth factors for the organic fraction of the aerosol are estimated based on employing the ZdanovskiiStokes Robinson (ZSR) mixing rule. Representative values for a parameterization treating particle water uptake in both the sub- and supersaturated regimes are reported for incorporation into atmospheric models.

\section{Introduction}

Bovine emissions are major sources of methane $\left(\mathrm{CH}_{4}\right)$, nitrous oxide $\left(\mathrm{N}_{2} \mathrm{O}\right)$, and ammonia $\left(\mathrm{NH}_{3}\right)$; they are also the dominant anthropogenic source for amines (Schade and Crutzen, 1995). Ammonia is the dominant base in the atmosphere, efficiently neutralizing acidic substances. The main global sources of ammonia are from livestock waste, fertilizer applications, biomass burning, motor vehicle emissions, and coal combustion (Apsimon et al., 1987; Asman and Janssen, 1987; Kleeman et al., 1999; Anderson et al., 2003; Battye et al., 2003). Typical ammonia mixing ratios over continents range between 0.1 and $10 \mathrm{ppb}$ (Edgerton et al., 2007, and references therein), while levels as high as a few ppm have been reported near areas of extensive livestock operations (Rumburg et al., 2006).

The principal inorganic aerosol components involving ammonia are ammonium nitrate and ammonium sulfate. The formation of these inorganic salts depends on temperature, relative humidity $(\mathrm{RH})$, and concentrations of $\mathrm{NH}_{3}$, nitric

Published by Copernicus Publications on behalf of the European Geosciences Union. 
acid $\left(\mathrm{HNO}_{3}\right)$, and sulfur dioxide $\left(\mathrm{SO}_{2}\right)$. Ammonium nitrate tends to form after sulfuric acid is completely neutralized. Atmospheric ammonium nitrate generally obeys thermodynamic equilibrium with gaseous nitric acid and ammonia (Stelson et al., 1979; Doyle et al., 1979; Stelson and Seinfeld, 1982a, 1982b; Russell et al., 1983; Hildemann et al., 1984; Zhang et al., 2002; Takahama et al., 2004; Yu et al., 2005), although some studies have pointed out that factors such as mass transport limitations can, at times, result in departures from equilibrium (Wexler and Seinfeld, 1992; Meng and Seinfeld, 1996; Fridlind and Jacobson, 2000; Fridlind et al., 2000). The equilibrium between particulate ammonium nitrate and gaseous nitric acid and ammonia shifts to the gas phase as ambient temperature increases, and RH decreases. Similar to ammonia, amines undergo neutralization reactions with nitric and sulfuric acids to form amine salts (Mozurkewich, 1993; Stelson and Seinfeld, 1982a; Angelino et al., 2001; Murphy et al., 2007). The photooxidation of gas-phase amines has been shown to form aerosol based on recent laboratory experiments (Angelino et al., 2001; Murphy et al., 2007).

Gaseous amines, including methylamine, dimethylamine, trimethylamine, ethylamine, diethylamine, triethylamine, ethanoloamine, $n$-butylamine, amylamine, 1,4butanediamine, isobutylamine, and isopropylamine, have been identified in emissions from bovine sources (Mosier et al., 1973; Hutchinson et al., 1982; Schade and Crutzen, 1995; Rabaud et al., 2003; Ngwabie et al., 2005). Amine emission rates from animal husbandry sources are typically two to three orders of magnitude lower than those of ammonia (Schade and Crutzen, 1995; Ngwabie et al., 2005). Gaseous amines are also present in vehicular exhaust (Cadle and Mulawa, 1980; Westerholm et al., 1993), the marine atmosphere (Vanneste et al., 1987), biomass burning plumes (Lobert et al., 1991), as well as emissions from decaying organic matter, waste incineration, and sewage treatment plants (Manahan, 2005). Amine salts have sufficiently low vapor pressures to partition to the aerosol phase; moreover, they exhibit greater water-solubility as compared to other particulate organic nitrogen species (Milne and Zika, 1993; Gorzelska et al., 1994; Murphy and Thomson, 1997; Glagolenko and Phares, 1994; Abalos et al., 1999; Angelino et al., 2001; Makela et al., 2001; Tan et al., 2002; Zhang et al., 2002; Zhang and Anastasio, 2003; Maria et al., 2003; Beddows et al., 2004; Denkenberger et al., 2007; Murphy et al., 2007; Sorooshian et al., 2007a).

The availability of a massive, concentrated source of ammonia and amines offers a unique opportunity to probe the response of the resulting aerosol. During July 2007, the Center for Interdisciplinary Remotely Piloted Aircraft Studies (CIRPAS) Twin Otter probed the aerosol downwind of a major cattle feedlot in the San Joaquin Valley in California. The San Joaquin Valley, the major geographical feature in central California, is bordered on its west and east sides by mountain ranges and is characterized by relatively stagnant air circulation (Fig. 1a). Consequently, this region is one of the largest nonattainment areas for ozone and particulate matter in the United States (Chow et al., 2006). The San Joaquin Valley contains numerous animal husbandry operations, the largest of which is the focus of this study. This feedlot operation covers several hundred acres and contains up to 100000 head of cattle at any one time. Although gasphase measurements were not carried out, the presence of ammonia and amines is inferred from established emissions inventories from animal husbandry sources and from measurements of the ammonium and amine content of the aerosol downwind of the plume source.

The goal of the present study is to provide a comprehensive airborne characterization of the aerosol downwind of a major bovine source. First, the aircraft instrument payload and flight path strategy are presented. Detailed measurements were obtained for: meteorology, aerosol size distributions and number concentrations, aerosol composition, mixing state, refractive index, hygroscopic growth factors at three different relative humidities, and cloud condensation nucleus (CCN) behavior. Special attention is given to the sub- and supersaturated water uptake properties of the aerosol, and how these relate to chemical composition. Subsaturated hygroscopic growth factors for the organic fraction of the aerosol are reported based on a closure analysis employing the Zdanovskii-Stokes Robinson mixing rule. Subsaturated hygroscopic growth data are then compared to measured supersaturated CCN activity to evaluate the level of consistency between observed water uptake in the two regimes.

\section{Experimental methods}

The data on which the present study is based were acquired during two clear air flights in the San Joaquin Valley on 12 July 2007 and 30 July 2007 . Henceforth, these two flights will be termed flight A (12 July 2007) and flight B (30 July 2007). The aircraft total aerosol inlet, characterized by Hegg et al. (2005), provided sample air to instruments on the aircraft. The instrument payload on the Twin Otter aircraft is described elsewhere (http://www.cirpas.org), however, attention is given below to those instruments the data from which will be discussed in detail.

\subsection{Aerosol chemical composition (Aerodyne C-ToF- AMS)}

Chemical composition measurements for non-refractory aerosol species (sulfate, nitrate, ammonium, and organics) were performed using an Aerodyne compact Time of Flight Aerosol Mass Spectrometer (C-ToF-AMS; Drewnick et al., 2005). At the entrance to the instrument, an aerodynamic lens focuses particles with vacuum aerodynamic diameters between approximately $50 \mathrm{~nm}$ and $800 \mathrm{~nm}$ through a $3.5 \%$ 


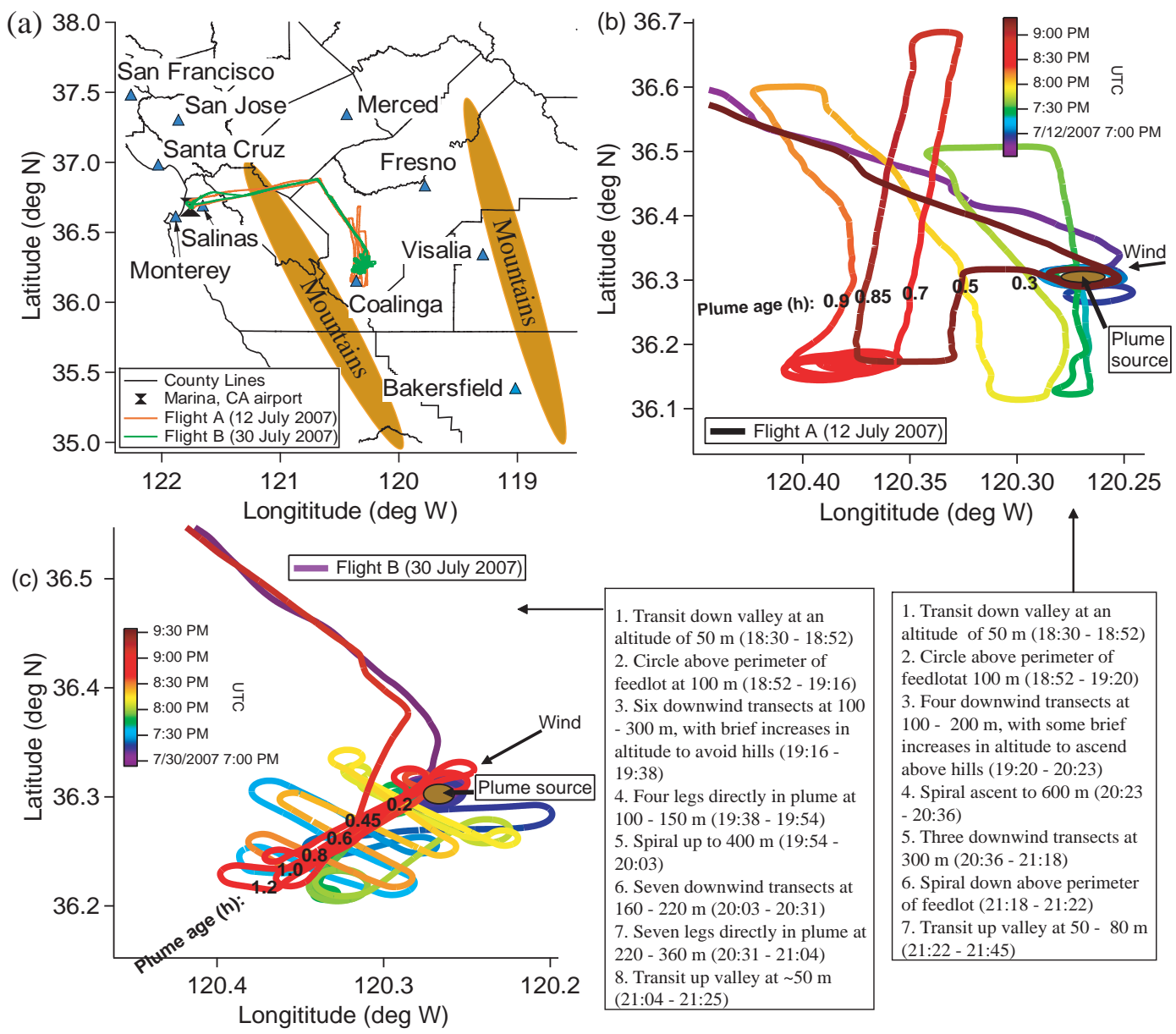

Fig. 1. (a) Complete flight tracks for the two flights in the San Joaquin Valley of California. The shaded mountain areas are meant to provide a relative view of how the San Joaquin Valley is bordered by major topographical features. (b)/(c) Detailed tracks for flights A (12 July 2007) and B (30 July 2007) with a step-by-step description of the aircraft maneuvers. Plume ages were calculated using downwind distance and average wind speed in the vicinity of the feedlot.

chopper and onto a tungsten vaporizer $\left(\sim 550^{\circ} \mathrm{C}\right)$ (Murphy et al., 2007). The chopper can be operated in three modes to gather either background mass spectra, ensemble average mass spectra over all particle sizes, or size-resolved mass spectra. Once vaporized, molecules undergo electron impact ionization and travel through a time of flight mass analyzer. The C-ToF-AMS detects the presence of amines in the form of characteristic amine peaks at $m / z$ 30, 56, and 86 (McLafferty and Turecek, 1993; Angelino et al., 2001; Murphy et al., 2007). The detection limit, calculated as three times the standard deviation of the noise for filtered air, is $<0.05 \mu \mathrm{g} / \mathrm{m}^{3}$ for all species measured.

The C-ToF-AMS can be used to calculate a quantity that will be referred to subsequently as excess nitrate. Excess nitrate is defined as the nitrate mass, derived from C-ToF-AMS spectra, remaining after both sulfate and nitrate have been fully neutralized by ammonium. A zero or slightly negative value indicates that sufficient ammonia exists to neutralize both sulfate and nitrate, while a positive value indicates that some nitrate is associated with other cations besides ammonium. C-ToF-AMS calibrations allow an assessment of the error associated with the excess nitrate calculation; introducing pure ammonium nitrate into the instrument should result in an excess nitrate value of zero. After flight A, calibrations were conducted with monodisperse ammonium nitrate particles ranging from $50 \mathrm{~nm}$ to $400 \mathrm{~nm}$ and mass concentrations ranging from $1.5 \mu \mathrm{g} / \mathrm{m}^{3}$ to $7.0 \mu \mathrm{g} / \mathrm{m}^{3}$, similar to concentrations in flight. Thirty-three calibration points were collected that exhibited an average excess nitrate of $0.08 \pm 0.31 \mu \mathrm{g} / \mathrm{m}^{3}$. Similarly during a calibration on the day of flight B, $350 \mathrm{~nm}$ and $400 \mathrm{~nm}$ ammonium nitrate particles were introduced into the instrument at levels near $\sim 3 \mu \mathrm{g} / \mathrm{m}^{3}$, which exceeds the peak nitrate concentration observed during the flight. The average excess nitrate was $-0.014 \pm 0.095 \mu \mathrm{g} / \mathrm{m}^{3}(n=17)$. As will be shown, ambient excess nitrate concentrations in the plume aerosol significantly exceeded the background values for pure ammonium nitrate. 
Nitrate species can be detected by peaks at $\mathrm{m} / \mathrm{z} 30$ and 46 . A problem innate to $\mathrm{C}$-ToF-AMS unit mass-resolution spectra is differentiating between $\mathrm{NO}^{+}, \mathrm{CH}_{2} \mathrm{O}^{+}$, and $\mathrm{C}_{2} \mathrm{H}_{6}^{+}$, all of which give peaks at $\mathrm{m} / \mathrm{z} 30$. If the contribution of organic fragments to the signal at $\mathrm{m} / \mathrm{z} 30$ is not correctly accounted for, the mass of nitrate, as inferred from $\mathrm{NO}^{+}$, can be overestimated. A relatively conservative approach is to calculate nitrate mass using the peak intensity at $m / z 46\left(\mathrm{NO}_{2}^{+}\right)$, which rarely corresponds to an organic fragment (McLafferty and Turecek, 1993). Calibration of the instrument with pure ammonium nitrate allows observation of the ratio of the peak intensities at $m / z, 30$ and 46 when $\mathrm{NO}^{+}$and $\mathrm{NO}_{2}^{+}$are present without organic interference. During such a calibration conducted after flight A, the peak at $\mathrm{m} / \mathrm{z}, 30$ was observed to be 2.2 times that at $\mathrm{m} / \mathrm{z}$ 46. Thus, for this flight, nitrate mass at $\mathrm{m} / \mathrm{z} 30$ was calculated to be 2.2 times the mass at $m / z 46$. Based on calibrations on the day of flight B, the peak at $\mathrm{m} / z$ 30 was observed to be 2.8 times that at $\mathrm{m} / \mathrm{z} 46$. The two calibrations were seventeen days apart, and instrumental drift is responsible for the difference in the $\mathrm{m} / \mathrm{z}, 30: 46$ ratio between the two days; typical values observed with this instrument range between two and three. The mass remaining at $\mathrm{m} / \mathrm{z}$ 30 after the nitrate contribution is subtracted is assumed to be organic species, including amines, which often exhibit a major peak here.

\subsection{Aerosol chemical composition (PILS)}

Water-soluble aerosol chemical composition was measured by a particle-into-liquid sampler (PILS, Brechtel Mfg Inc.; Sorooshian et al., 2006a). In the PILS, submicrometer ambient particles are grown into droplets sufficiently large to be collected by inertial impaction for subsequent chemical analysis. At the entrance to the instrument a series of three denuders (URG and Sunset Laboratories) remove inorganic (basic and acidic) and organic gases that would otherwise bias aerosol measurements. The impacted droplets are delivered to a rotating carousel containing 72 vials, with each vial containing material representing a period of $\sim 5 \mathrm{~min}$ of flight, or alternatively, a distance of $15 \mathrm{~km}$ in flight (aircraft speed $\sim 50 \mathrm{~m} / \mathrm{s}$ ). The contents of the vials are subsequently analyzed off-line using a dual ion chromatography (IC) system (ICS-2000, Dionex Inc.) for simultaneous anion and cation analysis.

The PILS-IC instrument uncertainty has been established as $\pm 7 \%$, and the detection limit (calculated as air-equivalent concentration of the lowest concentration standard that is distinct from baseline noise in the IC plus three times the standard deviation of this measurement) is $<0.1 \mu \mathrm{g} / \mathrm{m}^{3}$ for the inorganic ions $\mathrm{Na}^{+}, \mathrm{NH}_{4}^{+}, \mathrm{K}^{+}, \mathrm{Mg}^{2+}, \mathrm{Ca}^{2+}, \mathrm{Cl}^{-}$, $\mathrm{NO}_{2}^{-}, \mathrm{NO}_{3}^{-}$, and $\mathrm{SO}_{4}^{2-}$ ) and $<0.01 \mu \mathrm{g} / \mathrm{m}^{3}$ for the organic acid ions (carboxylic acids with one to nine carbon atoms) (Sorooshian et al., 2007b). The PILS-IC technique has been demonstrated to speciate amines, including ethylamine, diethylamine, triethylamine, methylamine, dimethylamine, and trimethylamine (Murphy et al., 2007); however, only ethylamine and diethylamine were measured above detection limits $\left(0.01 \mu \mathrm{g} / \mathrm{m}^{3}\right)$ in the present study. It should be noted that ammonium and ethylamine co-elute in the IC cation column; however, ethylamine was detected at sufficiently high concentrations for its peak to be distinguishable from that of ammonium. The reported concentrations of ethylamine represent a lower limit due to this co-elution effect. Since acetate, lactate, and glycolate also co-elute, these three species are reported as a collective mass using the calibration equation of acetate; therefore, the contribution of acetate reported is likely an overestimate. As compared to acetate, using the calibration equation of glycolate would reduce the estimates by $<10 \%$.

An important issue during this study was the potential for denuder breakthrough in the PILS because the sampling site represents the most concentrated ambient source of ammonia and amines encountered by this PILS. The denuders have been shown to successfully remove gaseous amine species in laboratory chamber experiments (Murphy et al., 2007); estimated initial mixing ratios for gaseous amines in those experiments ranged between 50-500 ppb, which is expected to represent levels expected in areas of intense animal husbandry. To check for evidence of ammonia breakthrough, the ammonium levels measured by the PILS and C-ToF-AMS, which is not prone to gaseous artifacts, are compared. For the following calculations it is assumed that the C-ToF-AMS collection efficiency for ammonium was constant throughout the flights and was identical to that of sulfate, even though external mixing was evident. The average of the ammonium ratio (PILS:C-ToF-AMS) was $0.90 \pm 0.11$ during flight $A$ and $0.87 \pm 0.21$ during flight $\mathrm{B}$. There was no clear enhancement in the ratio of PILS:C-ToF-AMS ammonium levels within the plume either flight. These data suggest that ammonia breakthrough did not lead to a positive artifact in the PILS, and even if so, it was masked by some other effect such as volatilization of ammonium in the PILS or an inaccurate collection efficiency applied to C-ToF-AMS ammonium data. Sorooshian et al. (2006a) showed that approximately $12 \%$ of ammonium in laboratory-generated ammonium sulfate particles is lost by volatilization at similar PILS operating conditions as implemented during this study, and the PILS data here are corrected for this $12 \%$. Therefore, it is uncertain as to why the PILS ammonium levels were on average less than those of the C-ToF-AMS.

\subsection{Aerosol hygroscopicity and refractive Index (DASH- SP)}

A differential aerosol sizing and hygroscopicity spectrometer probe (DASH-SP; Brechtel Mfg Inc.; Sorooshian et al., 2008) was included in the instrument payload on the aircraft. The DASH-SP consists of a single classification differential mobility analyzer (DMA) followed by a set of parallel hygroscopic growth chambers operated at different relative 
humidities. A 0.5 LPM aerosol sample flow passes first through a Nafion drier, and then through a ${ }^{210}$ Po neutralizer that brings the dried particles to a stable, steady-state charge distribution. A cylindrical DMA selects particles in a narrow interval of mobility-equivalent diameters in the 0.1 to $1.0 \mu \mathrm{m}$ range. The classified aerosol leaving the DMA is split into five separate flows. In one of the five streams, the total concentration of classified particles is determined using an integral TSI Model 3831 water-based condensation particle counter (CPC). The remaining four classified aerosol flows pass through a Nafion humidifier (Perma Pure, LLP, Model MD-070-24FS-4) to achieve thermodynamic equilibrium with water vapor at a constant, predetermined RH. The four conditioned aerosol flows pass directly to dedicated, custom-built OPCs ( $\lambda=532 \mathrm{~nm}$, World Star Technologies, Model TECGL-30) designed to size particles in the $100 \mathrm{~nm}$ to $3 \mu \mathrm{m}$ diameter size range. An iterative data processing algorithm quantifies an "effective" aerosol refractive index that is used to calculate hygroscopic growth factors $\left(\mathrm{GF}=D_{p \text {, wet }} / D_{p \text {, dry }}\right)$ corrected for the refractive-index dependence of the OPC response (Sorooshian et al., 2008). During this study, the DASH-SP provided simultaneous measurements of GFs at different RHs for dry DMA-selected particle diameters between $D_{p}=150-200 \mathrm{~nm}$. One humidifier was operated dry $(\mathrm{RH}<8 \%)$, and the other three were at RHs of $74 \%, 85 \%$, and $92 \%$. (No data from the $\mathrm{RH}=85 \%$ channel were available during flight A.) The uncertainty associated with growth factor measurements is $\sim \pm 4.5 \%$, and the uncertainty in the RH is $\pm 1.5 \%$.

\subsection{Cloud Condensation Nuclei Counter (CCNc)}

A continuous flow thermal gradient cloud condensation nuclei counter (CCNc, Droplet Measurement Technologies Inc.; Roberts and Nenes, 2005; Lance et al., 2006) was used to quantify the number of particles that activate at supersaturations ranging from $0.1 \%$ to $0.6 \%$. In the instrument a supersaturation is generated in an axisymmetric flow by applying a constant streamwise temperature gradient, using three sets of thermal electric coolers across a wetted column. At the exit of the CCNc column, those particles that activate and grow sufficiently large $\left(D_{p}>0.75 \mu \mathrm{m}\right)$ for detection by an OPC were quantified. The activated fraction is determined as the ratio of the $\mathrm{CCN}$ number concentration to the total particle $(\mathrm{CN})$ number concentration.

The $\mathrm{CCNc}$ was calibrated numerous times throughout this study and a brief description of the procedure now follows; we refer the reader to Appendix A for a more detailed explanation. Dried ammonium sulfate particles are sent to a DMA (Model 3081L, TSI Inc.) for size selection. The resulting monodisperse aerosol stream is split and sent to both a condensation particle counter (Model 3010, TSI Inc.) and a continuous-flow streamwise thermal gradient chamber (operated at constant flow rate, temperature gradient, and pressure) to measure $\mathrm{CN}$ and $\mathrm{CCN}$, respectively. The level of supersaturation in the instrument is determined from the minimum dry particle diameter, $D_{p 50}$ (dry diameter for which the $\mathrm{CCN} / \mathrm{CN}=0.50$ ), that activates in the instrument. The instrument supersaturation is related to $D_{p 50}$ by applying Köhler theory assuming ammonium sulfate has a density of $1760 \mathrm{~kg} / \mathrm{m}^{3}$, surface tension of water, molar mass of $0.132 \mathrm{~kg} / \mathrm{mol}$, and an effective van't Hoff factor of 2.5; studies have found the latter value to lie between 2 and 2.5 (Gerber et al., 1977; Brechtel and Kreidenweis, 2000; Kumar et al., 2003; Rose et al., 2008).

\subsection{Size distributions and particle number concentration}

Aerosol size distribution data were obtained by a DMA $\left(D_{p}\right.$ $=10-800 \mathrm{~nm}$ ) and an external passive cavity aerosol spectrometer probe $(0.1-3 \mu \mathrm{m})$ (PCASP, PMS Inc., modified by DMT Inc.). Particle number concentrations were quantified with two condensation particle counters (CPC Model 3010, TSI Inc., $D_{p}>10 \mathrm{~nm}$; UFCPC Model 3025, TSI Inc., $D_{p}>3 \mathrm{~nm}$ ). When the two CPCs experienced electrical saturation, particle number concentrations from the DMA are reported. The DMA time resolution is $74 \mathrm{~s}$ as opposed to $1 \mathrm{~s}$ for the CPCs.

\subsection{Flight strategy}

Complete flight tracks from flights A and B are shown in Fig. 1a. Both flights were intended to resemble each other in the time of the day and flight path. Starting from the Marina, CA airport, the aircraft transited east before descending to $50 \mathrm{~m}$ above the surface of the San Joaquin Valley. Then the aircraft flew southeast directly towards the feedlot, approaching to within one kilometer of the feedlot. A close-up of the flight tracks near the plume source with step-by-step details of the flight strategy is shown in Fig. $1 \mathrm{~b}$ and c. In each flight, the Twin Otter circled above the perimeter of the source several times, performed a spiral ascent to characterize the meteorological profile, performed several downwind transects of the plume at various altitudes below the boundary layer top, flew directly in the plume for several legs (only flight B), and transited northwest back up the valley. Sampling lasted for more than three hours starting just before noon during both flights. The feedlot operation is slightly larger than $3 \mathrm{~km}^{2}$ in area ( $\sim 800$ acres). The feedlot is bordered on the west side by the Interstate 5 roadway, which is a major transportation route and source of vehicular emissions, connecting northern and southern California.

\section{Results}

\subsection{Meteorology}

Figures 2 (flight A) and 3 (flight B) display the time evolution of meteorological and particle number concentration data, while Fig. 4 presents vertical profiles. During flight 


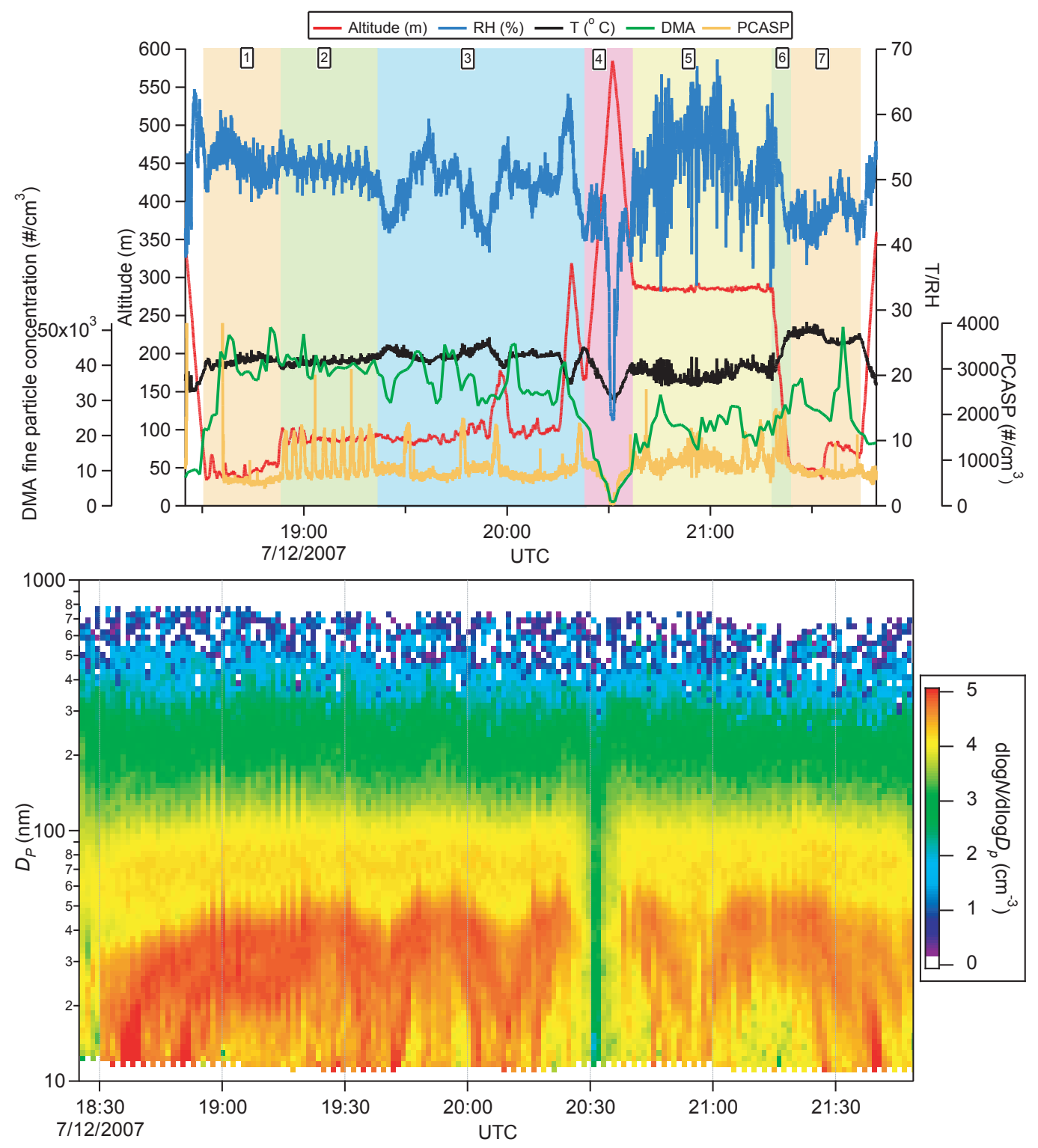

Fig. 2. Upper panel: time series of particle number concentration and meteorological data for flight A. Lower panel: time series of aerosol size distribution. The number labels at the top of each shaded block correspond to the respective flight segment listed in Fig. 1.

B, ambient temperatures $\left(27.5 \pm 2.4^{\circ} \mathrm{C}\right)$ were higher and RHs $(25.8 \pm 5.9 \%)$ were lower than observed in flight A $\left(21.8 \pm 2.3^{\circ} \mathrm{C} ; 49.0 \pm 7.8 \%\right)$. During both flights, the aircraft performed three vertical profiles of the boundary layer. The temperature inversions were weak $\left(<1^{\circ} \mathrm{C}\right)$, so decreases in $\mathrm{RH}$ and particle number concentrations, as quantified by the DMA and PCASP, are used as indicators for inversion layers. The boundary layer exhibited multiple inversions, the highest of which was observed at the end of the flights ( 03:00 p.m. local time) at $\sim 630 \mathrm{~m}$. The depth of the inversion layers increased with time as the surface warmed. The vertical temperature and RH profiles, and the relatively uniform particle concentrations with altitude (Fig. 4) provide evidence for a vigorously-mixed boundary layer, as was previously observed by Neuman et al. (2003) in the San Joaquin Valley in May 2002.

Five-day back-trajectories, computed using the NOAA HYSPLIT model (Draxler and Rolph, 2003), show that the background air during flight $\mathrm{A}$ originated over the Pacific Ocean, whereas the background air during flight B was transported over land from the north (Fig. 5). This suggests that the background aerosol in flight A may have carried the signature of cleaner marine air, while that measured during flight B was more exposed to urban and agricultural emissions. 

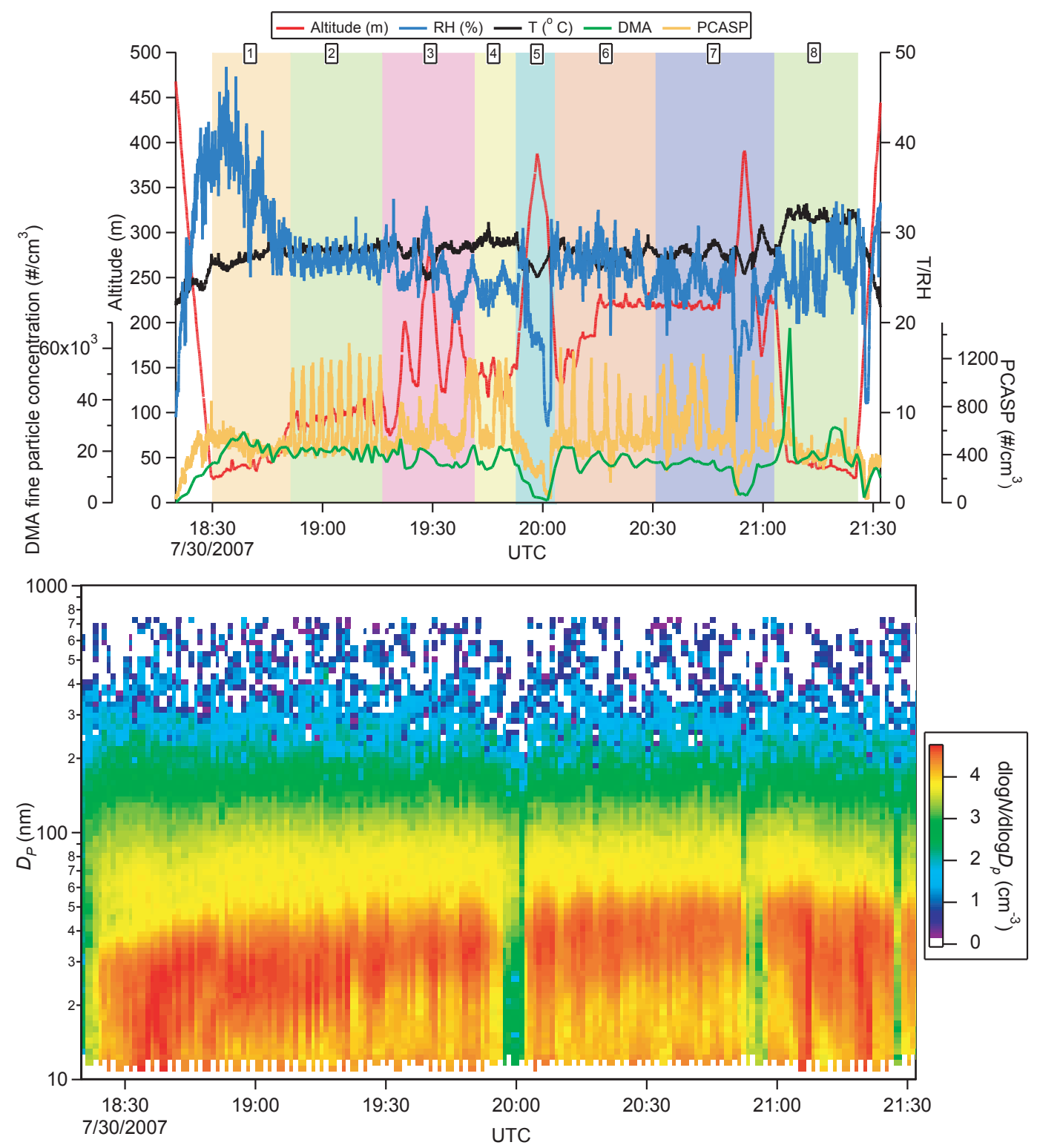

Fig. 3. Upper panel: time series of particle number concentration and meteorological data for flight B. Lower panel: time series of aerosol size distribution. The number labels at the top of each shaded block correspond to the respective flight segment listed in Fig. 1.

\subsection{Particle number concentrations and size distributions}

Average submicrometer particle number concentrations in the plume were $30528 \pm 8987 \mathrm{~cm}^{-3}$ (flight A) and $16606 \pm 4286 \mathrm{~cm}^{-3}$ (flight B) (Table 1). Particle number concentrations in and out of the plume were similar, indicating the absence of significant emissions of particles from the source. (As noted in Sect. 3.3, nitrate enhancement is used to identify the location of the plume.) During the downwind plume transects, number concentrations decreased slightly with increasing altitude until a sharp decrease near the top of the boundary layer to below $300 \mathrm{~cm}^{-3}$ (flight A) and $800 \mathrm{~cm}^{-3}$ (flight B) at altitudes of $550 \mathrm{~m}$ and $400 \mathrm{~m}$, respec- tively. The ratio of the number concentration of particles with $D_{p}>3 \mathrm{~nm}$ to the number concentration of particles with $D_{p}>10 \mathrm{~nm}$ was $1.1 \pm 0.1$ and $1.2 \pm 0.1$ for flights A and B, respectively. This ratio showed no difference in and out of the plume and decreased with altitude.

The vertical structure of the PCASP $\left(D_{p}=0.1-3 \mu \mathrm{m}\right)$ and $\mathrm{CPC}$ number concentrations were similar. Average PCASP concentrations in the plume for flights $\mathrm{A}$ and $\mathrm{B}$ were $1065 \pm 330$ and $675 \pm 220 \mathrm{~cm}^{-3}$, respectively, indicating that most of the particles were smaller than $100 \mathrm{~nm}$ in diameter. The number of 0.1 to $3 \mu \mathrm{m}$ diameter particles in the plume was enhanced by a factor of 2.5-3 times as much over that in the background aerosol. This is especially evident 

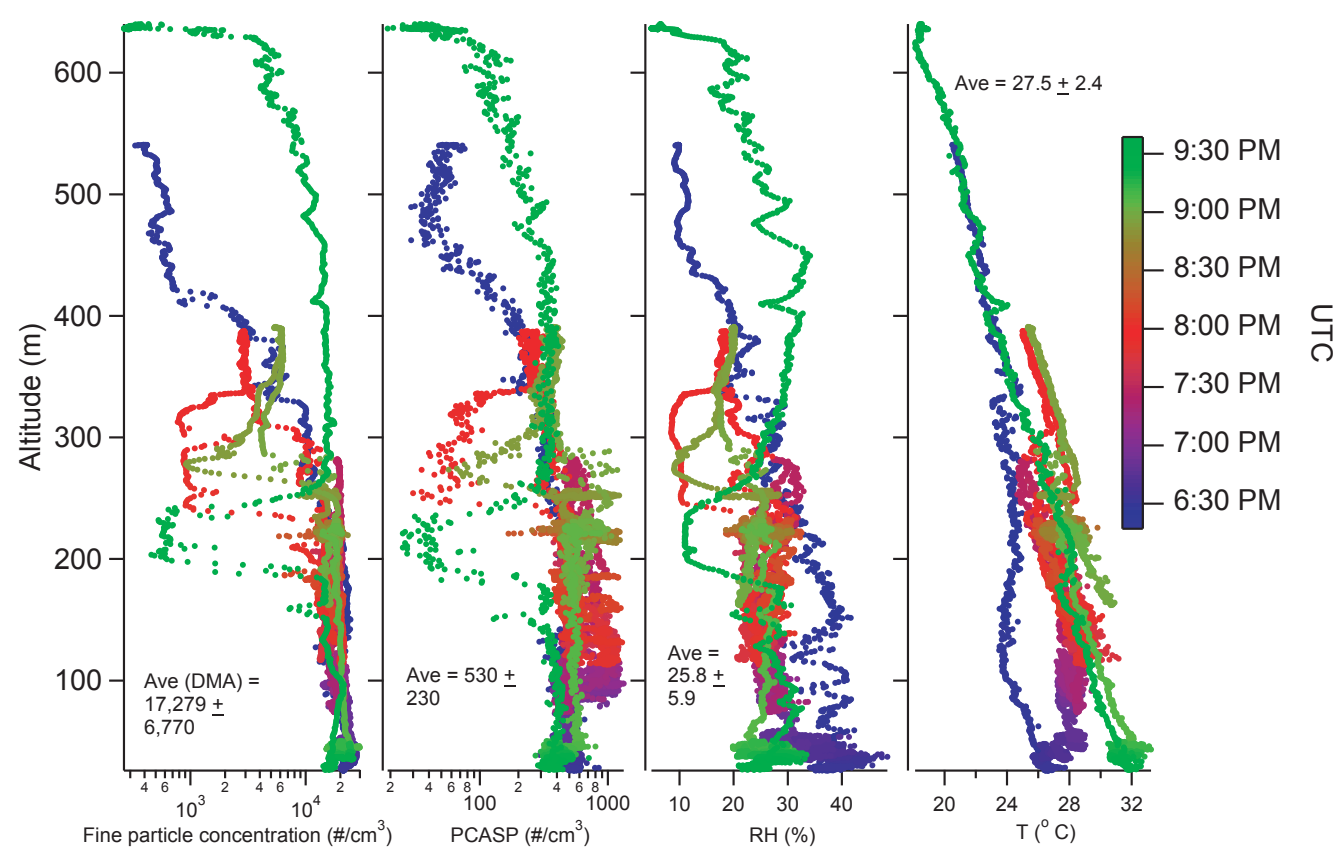

Fig. 4. Vertical profiles of particle number concentration and meteorological data for flights A (upper panel) and B (lower panel). For the submicrometer particle concentration data (CPC 3010), it should be noted that the absolute concentrations are not accurate due to electrical saturation of the instrument; these data are plotted because of the $1 \mathrm{~s}$ time resolution of the data. The DMA and CPC 3010 number concentrations were proportional throughout both flights, therefore, the CPC 3010 values are useful for qualitative purposes to identify the mixing layer height. DMA number concentrations indicated are accurate.

Table 1. Summary of in-plume and out-of-plume measurements of composition and particle number and mass concentration.

\begin{tabular}{|c|c|c|c|c|c|c|c|c|c|c|c|c|c|c|c|c|c|c|}
\hline & & & $\begin{array}{c}\text { Total } \\
\text { Mass } \\
\left(\mu \mathrm{g} / \mathrm{m}^{3}\right) \\
\end{array}$ & $\begin{array}{l}\text { Organic } \\
\left(\mu \mathrm{g} / \mathrm{m}^{3}\right)\end{array}$ & $\begin{array}{c}\mathrm{NO}_{3}^{-} \\
\left(\mu \mathrm{g} / \mathrm{m}^{3}\right)\end{array}$ & $\begin{array}{c}\mathrm{SO}_{4}^{2-} \\
\left(\mu \mathrm{g} / \mathrm{m}^{3}\right)\end{array}$ & $\begin{array}{c}\mathrm{NH}_{4}^{+} \\
\left(\mu \mathrm{g} / \mathrm{m}^{3}\right) \\
\end{array}$ & $\begin{array}{c}\text { Excess } \\
\mathrm{NO}_{3}^{-} \\
\left(\mu \mathrm{g} / \mathrm{m}^{3}\right) \\
\end{array}$ & $\begin{array}{c}{\left[\mathrm{NH}_{4}^{+}: \mathrm{SO}_{4}^{2-}\right]} \\
\text { molar ratio }\end{array}$ & $\begin{array}{c}\% \\
\text { Organic }\end{array}$ & $\begin{array}{c}\% \\
\mathrm{NO}_{3}^{-} \\
\end{array}$ & $\begin{array}{c}\% \\
\mathrm{SO}_{4}^{2-}\end{array}$ & $\begin{array}{c}\% \\
\mathrm{NH}_{4}^{+} \\
\end{array}$ & $\begin{array}{c}\text { DMA particle } \\
\text { concentration } \\
\left(\# / \mathrm{cm}^{3}\right)\end{array}$ & $\begin{array}{c}\text { (UFCPC } \\
3025: \mathrm{CPC} \\
3010)^{\mathrm{a}}\end{array}$ & $\begin{array}{c}\text { cToF- } \\
\text { AMS: } m / z \\
57: 44\end{array}$ & $\begin{array}{c}\text { cToF-AMS: } \\
m / z \text { 44/Total } \\
\text { Organic }\end{array}$ & $\begin{array}{c}\mathrm{O}: \mathrm{C} \\
\text { atomic } \\
\text { ratio }^{\text {b }} \\
\end{array}$ \\
\hline \multirow{4}{*}{ Flight A } & In plume & AVE & 10.48 & 6.48 & 0.93 & 2.06 & 1.02 & 0.04 & 2.64 & 61.9 & 8.6 & 19.8 & 9.7 & 30528 & 1.1 & 0.07 & 0.10 & 0.45 \\
\hline & & ST DEV & 1.64 & 0.98 & 0.40 & 0.24 & 0.23 & 0.50 & 0.51 & 2.6 & 2.4 & 1.7 & 1.7 & 8987 & 0.0 & 0.01 & 0.01 & 0.02 \\
\hline & Out of & AVE & 8.01 & 5.10 & 0.30 & 1.81 & 0.80 & -0.16 & 2.38 & 63.5 & 3.7 & 22.8 & 10.1 & 30778 & 1.1 & 0.07 & 0.10 & 0.45 \\
\hline & plume & ST DEV & 1.48 & 1.07 & 0.11 & 0.31 & 0.17 & 0.41 & 0.47 & 3.3 & 1.1 & 2.6 & 1.8 & 11026 & 0.0 & 0.02 & 0.01 & 0.02 \\
\hline \multirow[t]{4}{*}{ Flight B } & In plume & AVE & 4.53 & 2.46 & 1.08 & 0.54 & 0.44 & 0.02 & 4.6 & 55.5 & 22.7 & 12.3 & 9.6 & 16606 & 1.2 & 0.07 & 0.11 & 0.48 \\
\hline & & ST DEV & 0.87 & 0.29 & 0.50 & 0.10 & 0.14 & 0.34 & 2.25 & 6.4 & 7.3 & 3.0 & 2.1 & 4286 & 0.1 & 0.02 & 0.01 & 0.04 \\
\hline & Out of & AVE & 2.65 & 1.73 & 0.19 & 0.56 & 0.19 & 0.00 & 1.94 & 63.1 & 7.2 & 23.1 & 7.0 & 18139 & 1.2 & 0.09 & 0.12 & 0.53 \\
\hline & plume & ST DEV & 0.95 & 0.70 & 0.12 & 0.26 & 0.10 & 0.21 & 1.42 & 11.9 & 2.4 & 11.0 & 3.8 & 8910 & 0.1 & 0.08 & 0.02 & 0.09 \\
\hline
\end{tabular}

a The ratio of the particle number concentration for $D_{p}>3 \mathrm{~nm}$ (UFCPC 3025) to that for $D_{p}>10 \mathrm{~nm}$ (CPC 3010).

$\mathrm{b}$ The O:C atomic ratio was calculated using the data inventory and slope equation presented by Aiken et al. (2008; Fig. 4b)

by the increase in number concentration $\left(D_{p}>100 \mathrm{~nm}\right)$ observed when passing through the beginning of the plume over the perimeter of the source (upper panels of Figs. 2 and 3; see the flight segments labeled " 2 " when the aircraft was circling the perimeter of the plume source); this likely is a result of smaller particles growing into this size range. However, the increase in number concentration for particles with $D_{p}=0.1-$ $3 \mu \mathrm{m}$ was not sufficiently large to result in a significant difference in the submicrometer number concentration $\left(D_{p}=0.01-\right.$ $1 \mu \mathrm{m})$ in and out of the plume.

Aerosol number and volume distributions were similar both between the two flights, and in and out of the plume. Multiple modes normally existed in the number and volume distributions. A number concentration mode was generally present between $D_{p}=20-60 \mathrm{~nm}$, with a weaker mode between $D_{p}=60-100 \mathrm{~nm}$ (lower panels of Figs. 2 and 3). There was also a dominant number concentration mode, which will be referred to as the nucleation mode, at sizes smaller than the detection limit of the DMA $(10 \mathrm{~nm})$; this mode is evident from the difference in number concentration measured by the DMA and the UFCPC 3025 . Volume concentration modes existed at $D_{p}=30-60 \mathrm{~nm}, D_{p} \sim 100 \mathrm{~nm}$, and frequently at $D_{p}>100 \mathrm{~nm}$. The number and volume distributions in the plume shifted slightly to larger sizes with downwind distance from the plume source. 

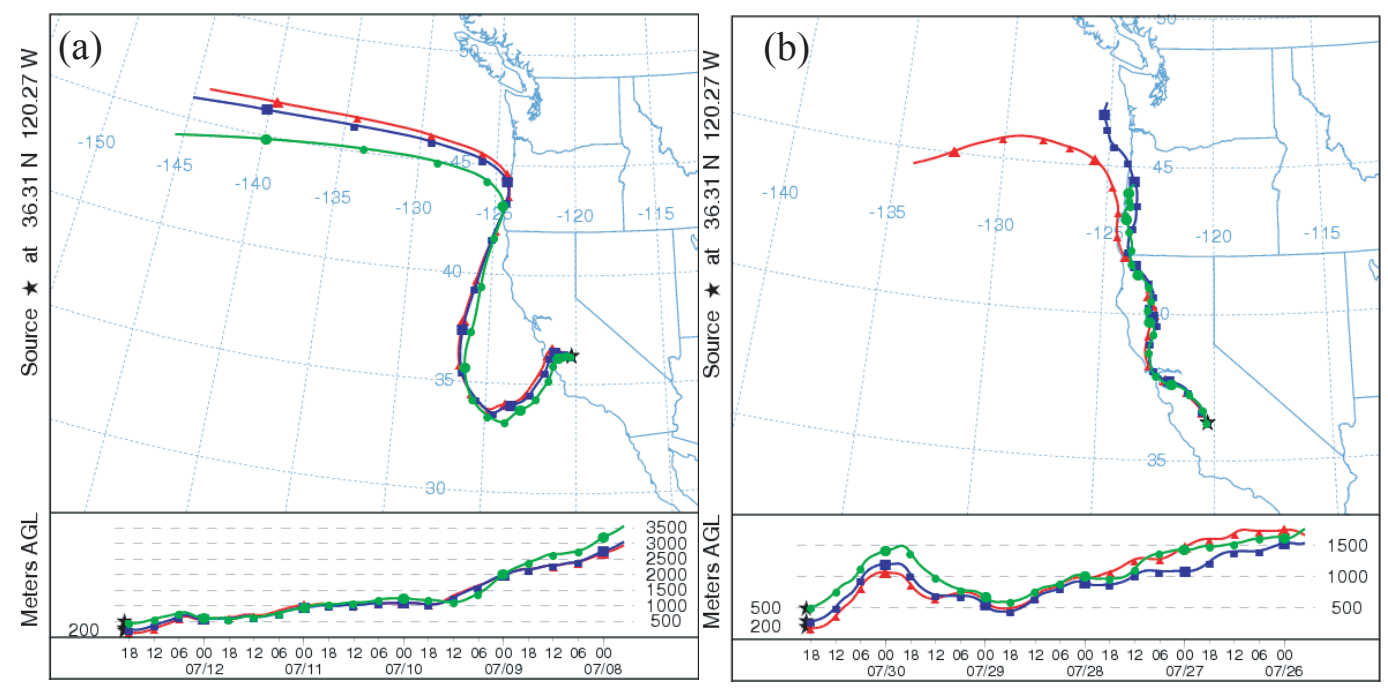

Fig. 5. HYSPLIT five-day backward trajectory analysis for flights A (panel (a)) and B (panel (b)). Six hours of time separate each marker on the trajectories.

\subsection{Submicrometer aerosol chemical composition}

Figure 6 (time series), Figs. 7 and 8 (spatial distribution), and Fig. 9 (vertical distribution) summarize the submicrometer aerosol composition data, in addition to Table 1, which reports the background and in-plume composition for both flights. The reported total organic mass is non-refractory organic mass that was measured by the C-ToF-AMS. The total aerosol mass is determined as the sum of inorganic mass, as determined by the PILS and C-ToF-AMS, and non-refractory organic mass from the C-ToF-AMS. Nitrate enhancement is used to define the location of the plume. Then, knowing where the plume is, local enhancements in other species concentrations and aerosol properties can be determined. Plume ages are noted on the spatial plots in Fig. $1 \mathrm{~b}$ and $\mathrm{c}$ and were calculated using downwind distance and average wind speed in the vicinity of the source. The highest plume age encountered in flights A and B was $0.9 \mathrm{~h}$ and $1.2 \mathrm{~h}$, respectively.

\subsubsection{Total aerosol mass and major components}

The average total aerosol mass in the boundary layer was $8.85 \pm 1.79 \mu \mathrm{g} / \mathrm{m}^{3}$ and $3.40 \pm 0.98 \mu \mathrm{g} / \mathrm{m}^{3}$ during flights A and $\mathrm{B}$, respectively, with significant enhancements in the plume (Table 1). The highest concentrations, $17.07 \mu \mathrm{g} / \mathrm{m}^{3}$ (flight A) and $6.27 \mu \mathrm{g} / \mathrm{m}^{3}$ (flight B), occurred in the plume while the lowest concentrations were observed at the highest altitudes when the aircraft performed spiral ascents (flight $\mathrm{A}=1.40$ $\mu \mathrm{g} / \mathrm{m}^{3}$; flight $\mathrm{B}=0.24 \mu \mathrm{g} / \mathrm{m}^{3}$ ).

Overall, organic species dominated the total mass. Organics accounted for $61.9 \% \pm 2.6 \%$ (flight $\mathrm{A}$ ) and $55.5 \%$ $\pm 6.4 \%$ (flight B) of the plume aerosol mass, and $63.5 \% \pm$ $3.3 \%$ (flight A) and $63.1 \% \pm 11.9 \%$ (flight B) of the background aerosol mass. The organic mass concentration in the plume was $6.48 \pm 0.98 \mu \mathrm{g} / \mathrm{m}^{3}$ (flight A) and $2.46 \pm 0.29$ $\mu \mathrm{g} / \mathrm{m}^{3}$ (flight B), and in the background aerosol was 5.10 $\pm 1.07 \mu \mathrm{g} / \mathrm{m}^{3}$ (flight A) and $1.73 \pm 0.70 \mu \mathrm{g} / \mathrm{m}^{3}$ (flight B). The next largest contributor to the particulate mass was either sulfate or nitrate, depending on the day and aerosol type, followed by either ammonium or nitrate (see Table 1). The ratio of organic mass to inorganic mass in the plume was $1.64 \pm$ 0.19 (flight A) and $1.30 \pm 0.39$ (flight $\mathrm{B}$ ), while the ratio in the background aerosol was $1.77 \pm 0.29$ (flight A) and 1.92 \pm 0.68 (flight B). Previous measurements in the San Joaquin Valley have also shown that organic aerosol contributes significantly to the fine particle mass (Chow et al., 1996; Neuman et al., 2003).

\subsubsection{Inorganic Aerosol}

Within the source plume, the levels of nitrate and ammonium increased significantly above their respective values in the background valley aerosol (Fig. 6 - 8). The ammoniumto-sulfate molar ratio is an important indicator of the level of partitioning of ammonium nitrate between the gas and aerosol phases. Since this ratio usually exceeded two, ammonia was available to foster partitioning of nitrate to the aerosol phase in the plume. The vertical distribution of nitrate and ammonium exhibited similar trends in each flight, unlike sulfate, which did not increase in concentration at plume altitudes ( 100 - $300 \mathrm{~m}$ ) (Fig. 9).

Generally, other inorganic species, including chloride, sodium, potassium, calcium, magnesium, and nitrite, did not contribute significantly $\left(>0.1 \mu \mathrm{g} / \mathrm{m}^{3}\right)$ to the aerosol mass. Many of these species are expected to be found primarily in the coarse particle fraction $\left(D_{p}>1 \mu \mathrm{m}\right)$, owing to their origins in sea salt $\left(\mathrm{Na}^{+}, \mathrm{Cl}^{-}\right)$and dust and soil $\left(\mathrm{Ca}^{2+}\right.$, 


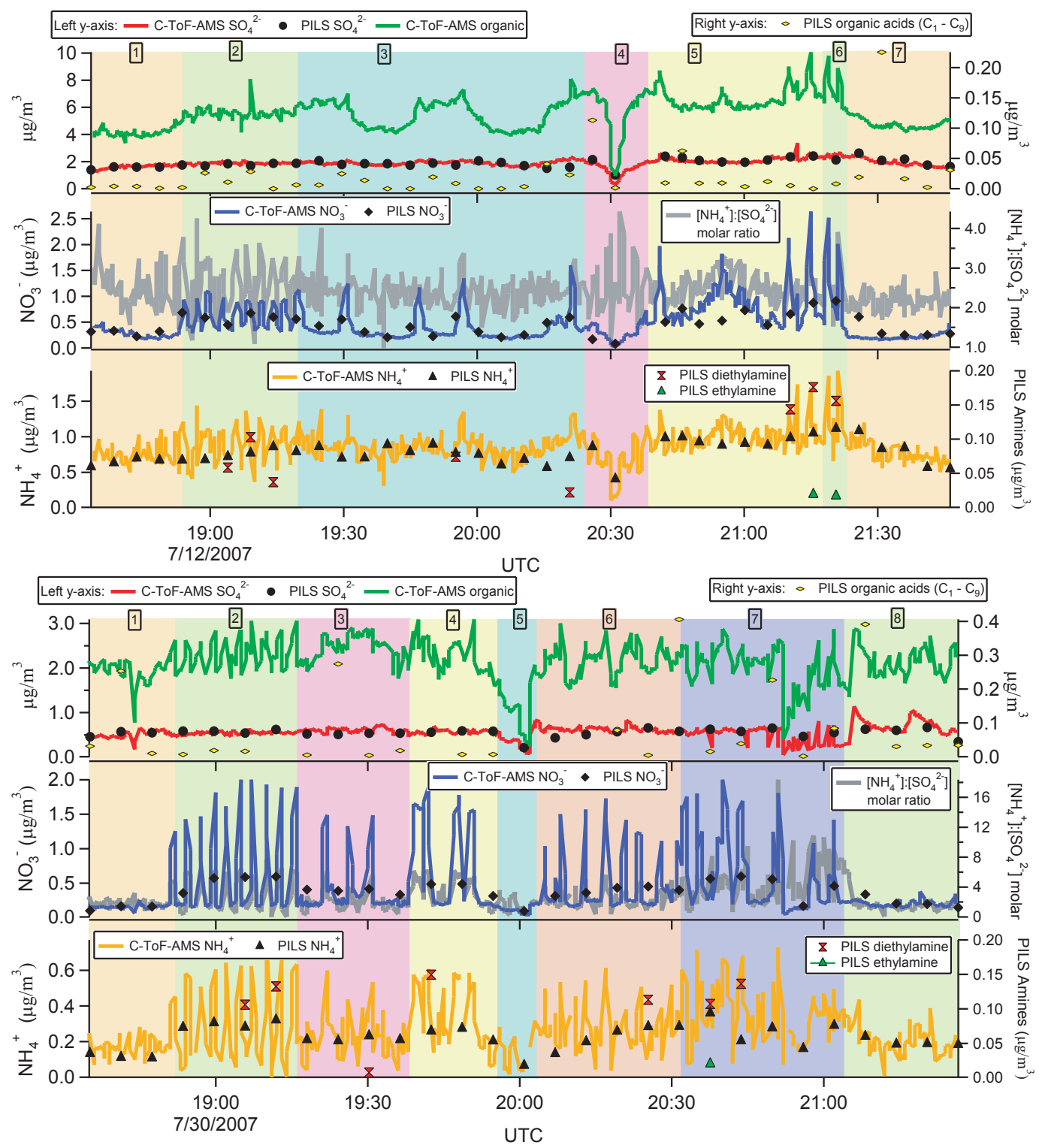

Fig. 6. Time series of PILS water-soluble aerosol composition and C-ToF-AMS composition for flights A (upper panel) and B (lower panel). The number labels for each shaded box correspond to the portion of each flight represented in Fig. 1. The shaded areas representing the plume are characterized by significant increases in organics, ammonium, nitrate, and amines. The ammonium-to-sulfate molar ratio exceeds 2.0 in the plume, allowing nitrate to partition into the aerosol phase. The multiple C-ToF-AMS spikes in the species concentrations cannot be resolved by the PILS since the 5-min time intervals for sample collection average out the quick plume passes with the longer legs outside of the plume. Agreement between the PILS and C-ToF-AMS is most evident for sulfate, since this species was relatively level in concentration during the flights.

$\left.\mathrm{Mg}^{2+}, \mathrm{Na}^{+}, \mathrm{K}^{+}\right)$. Magnesium, calcium, and potassium concentrations were all below detection limits $\left(<0.05 \mu \mathrm{g} / \mathrm{m}^{3}\right)$. Sodium and chloride were sparsely detected in both flights, usually in the background aerosol during the transits, with concentrations near $\sim 0.1 \mu \mathrm{g} / \mathrm{m}^{3}$. Nitrite above detection limits was found in only one PILS sample $\left(0.10 \mu \mathrm{g} / \mathrm{m}^{3}\right)$ during flight $\mathrm{A}$ while circling the feedlot near the beginning of the flight $(\mathrm{UT} \sim 19: 00)$.

\subsubsection{Organic Aerosol}

The concentration of total organics, as determined by the CToF-AMS, in the plume aerosol significantly exceeded those in the background valley aerosol (Fig. 6-8). The vertical distribution of total organic concentrations was somewhat similar to those of nitrate and ammonium, with the exception that there was not as sharp an enhancement in concentration at plume altitudes, as was especially evident in flight B (Fig. 9). 

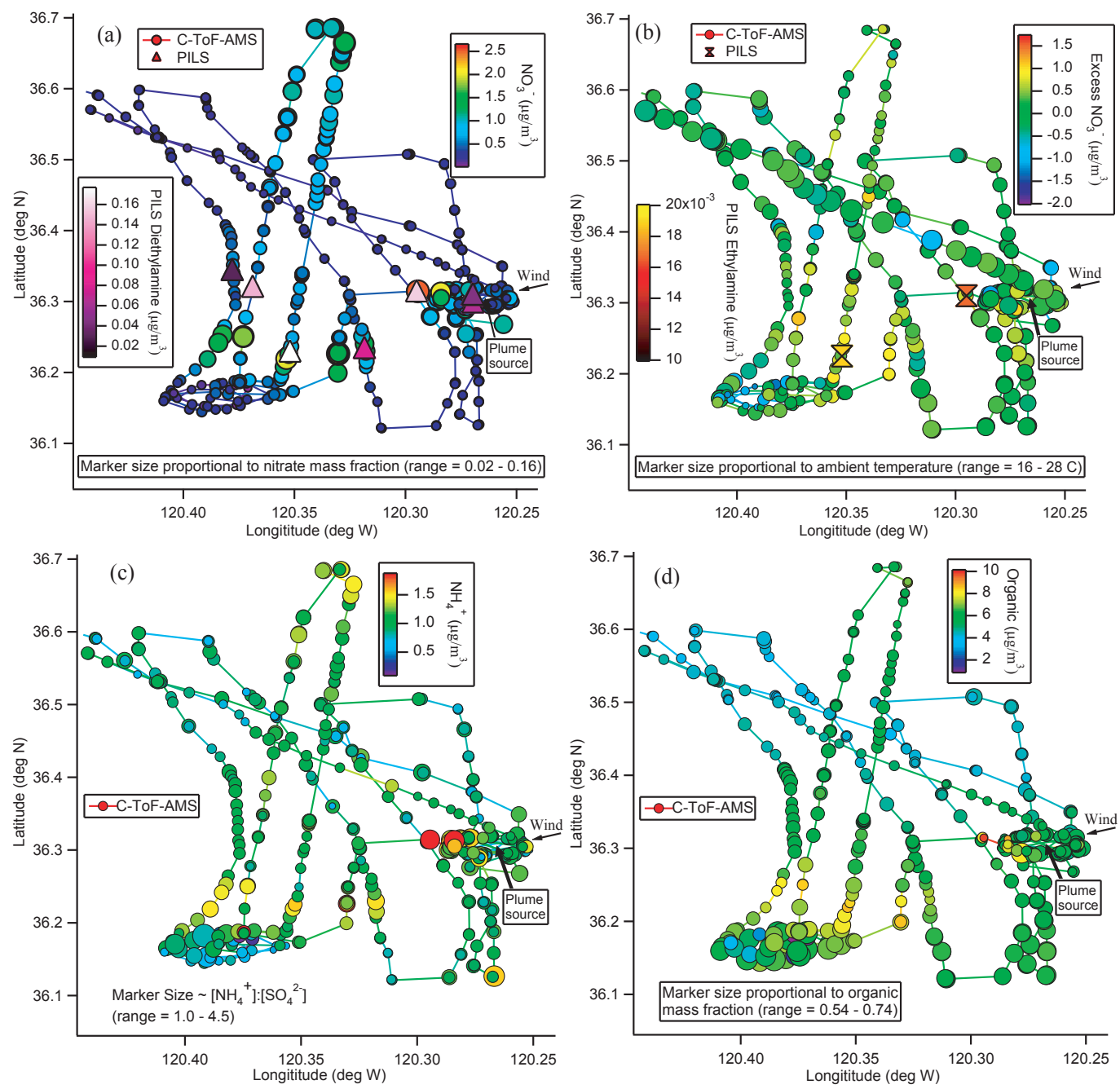

Fig. 7. Spatial distribution of various aerosol species during flight A. (a) C-ToF-AMS nitrate and PILS diethylamine, with marker size proportional to nitrate mass fraction; (b) Excess nitrate remaining after both sulfate and nitrate have been neutralized by ammonium (see Sect. 2.1 for further explanation), with marker size proportional to ambient temperature; (c) C-ToF-AMS ammonium, with marker size proportional to the ammonium-to-sulfate molar ratio; (d) C-ToF-AMS organic, with marker size proportional to organic mass fraction. The PILS markers are spatially placed wherever the aircraft was at the midpoint of the time when a particular sample was collected (after being corrected for liquid residence time in the instrument); therefore the amine markers are spatially distinct from the core of the plume (especially the two markers representing the highest plume ages).

Figure 10 shows the representative mass spectra of the organic fragments detected by the C-ToF-AMS in the background valley aerosol, the plume aerosol close to the source, and farther downwind. All non-organic contributions to the mass spectra have been removed using the methodology described in Allan et al. (2004); fragmentation at $\mathrm{m} / \mathrm{z} 30$ was further modified as described in Sect. 2.1. Figure 11 indicates that the signal at $m / z 30$ represents a large fragment for organics, including amines. The chemical signatures of the organic aerosol in the three categories appear to be quite similar. One difference, which is highlighted also in Fig. 10, is that the $m / z 30$ (common amine marker) peak intensity is enhanced by $\sim 150 \%$ at the closest point to the plume source as compared to background aerosol, and decreases by $\sim 25 \%$ at the farthest downwind distance. Figure 11 shows comparisons of the plume aerosol organic mass spectra to the background spectra for both flights. The overall organic aerosol appears to be similar in and out of the plume; however, peak intensities at $\mathrm{m} / \mathrm{z} 30,56$, and 86 are enhanced in plume. These are all peaks in the electron impact mass spectrum of amines, including diethylamine and triethylamine (McLafferty and Turecek, 1993; Angelino et al., 2001; Murphy et al., 2007). A similar analysis for plume organics close to the feedlot and farther downwind reveals no significant difference in most peaks, although the intensity of the $\mathrm{m} / \mathrm{z} 30$ peak decreases with increasing plume age; as will be discussed 

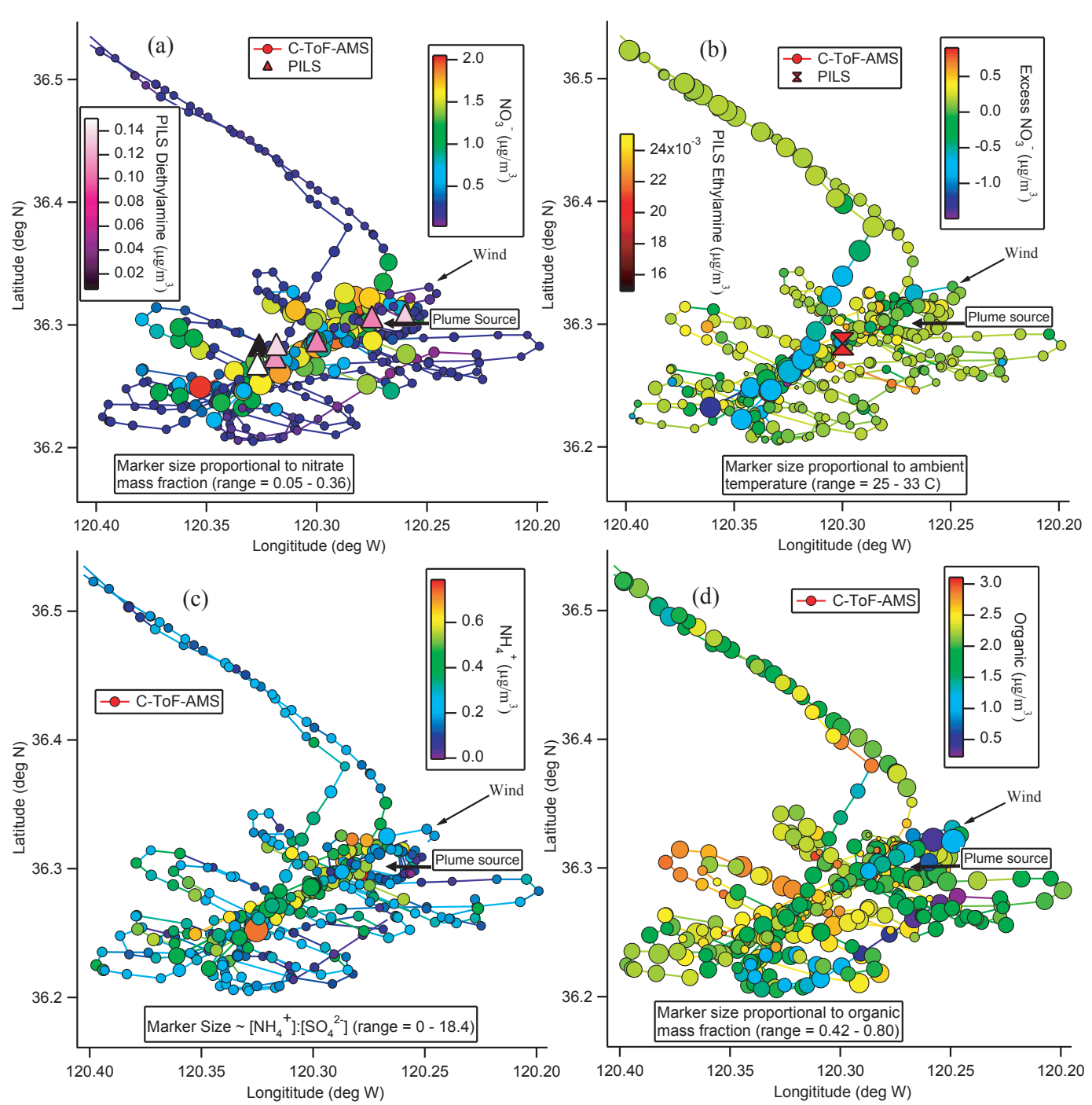

Fig. 8. Spatial distribution of various aerosol species during flight B. (a) C-ToF-AMS nitrate and PILS diethylamine, with marker size proportional to nitrate mass fraction; (b) Excess nitrate remaining after both sulfate and nitrate have been neutralized by ammonium (see Sect. 2.1 for further explanation), with marker size proportional to ambient temperature; (c) C-ToF-AMS ammonium, with marker size proportional to the ammonium-to-sulfate molar ratio; (d) C-ToF-AMS organic, with marker size proportional to organic mass fraction. The PILS markers are spatially placed wherever the aircraft was at the midpoint of the time when a particular sample was collected (after being corrected for liquid residence time in the instrument).

subsequently, this is likely attributed to increased partitioning of particulate amines to the gas phase to maintain thermodynamic equilibrium as the plume dilutes with background air. An analysis of the background valley aerosol spectra during the transit portions of the flights indicates that the organic aerosol composition was similar throughout the valley.

Two amines were detected by the PILS, diethylamine and ethylamine; these were found only in the plume (Figs. 68). Diethylamine reached higher concentrations (up to $0.18 \mu \mathrm{g} / \mathrm{m}^{3}$ and $6.0 \%$ of the organic mass) and was more abundant farther downwind of the feedlot as compared to ethylamine; diethylamine was observed at plume ages up to $0.9 \mathrm{~h}$ (flight A) and $0.7 \mathrm{~h}$ (flight B). Ethylamine was detected by the PILS only in three samples collected during the two flights. It was found immediately downwind of the feedlot up to plume ages of $0.7 \mathrm{~h}$ (flight A) and $0.3 \mathrm{~h}$ (flight B) at concentrations near $0.02 \mu \mathrm{g} / \mathrm{m}^{3}$, which corresponds to $0.8 \%$ of the total organic mass, as inferred from the C-ToF-AMS data.

The collective organic acid concentration, as determined by the PILS, reached levels of up to $0.23 \mu \mathrm{g} / \mathrm{m}^{3}$ (flight A) and $0.41 \mu \mathrm{g} / \mathrm{m}^{3}$ (flight B), accounting for $0.4 \%( \pm 0.8 \%)$ and $0.4 \%( \pm 0.6 \%)$ of the C-ToF-AMS total organic mass during flights A and B, respectively. Oxalate was the most abundant organic acid, followed by succinate, formate, and acetate. The concentration of the organic acids $\left(\mathrm{C}_{1}-\mathrm{C}_{9}\right)$ were not 

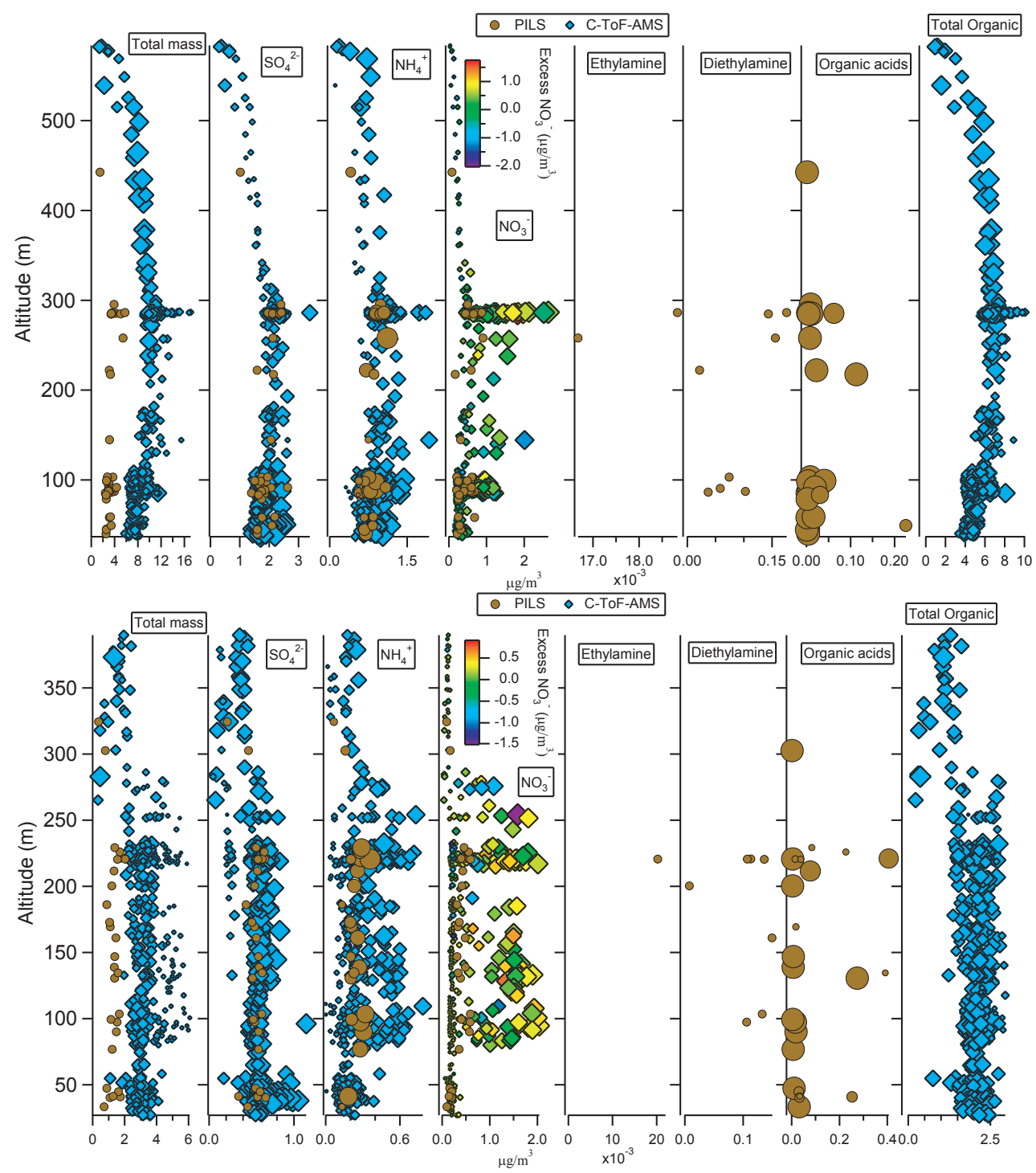

Fig. 9. Vertical distribution of total submicrometer particulate mass and species concentrations from both the PILS and C-ToF-AMS, for flights A (upper panel) and B (lower panel). The C-ToF-AMS marker sizes for "Total mass" are proportional to the organic:inorganic ratio. Marker sizes for the individual C-ToF-AMS species are proportional to the respective mass fraction of that species. Marker sizes for PILS "Organic acids" are proportional to the relative contribution by oxalate. Marker sizes for PILS ammonium are proportional to the ammonium-to-sulfate molar ratio. Total mass, nitrate, ammonium, and organics increase in concentration with increasing altitude up to $\sim 250-300 \mathrm{~m}$, before decreasing in both flights. C-ToF-AMS concentrations exceed those of the PILS for commonly detected species in the plume, especially nitrate and ammonium, since the PILS averages 5-min worth of aerosol composition whereas the C-ToF-AMS has a time resolution of $\sim 20-30 \mathrm{~s}$. Total PILS mass includes inorganics and organic acids, whereas total C-ToF-AMS mass includes inorganics and nonrefractory organic mass.

found to be correlated with those of total organics, amines, or any inorganic species.

\subsection{Aerosol mixing state}

Figure 12 shows speciated size distributions for the background and in-plume aerosol at various downwind distances for both flights. Organics, nitrate, and sulfate all appear to be externally mixed to some extent. This is especially clear when examining the plume aerosol at various downwind distances in flight $\mathrm{B}$; the distribution of nitrate aerosol grows in diameter, while the organic distribution shows relatively less growth and the sulfate distribution does not exhibit any corresponding shift in size. Speciated size distributions for the valley aerosol during transit are similar to the background aerosol in the vicinity of the feedlot, indicating chemically similar particles. 


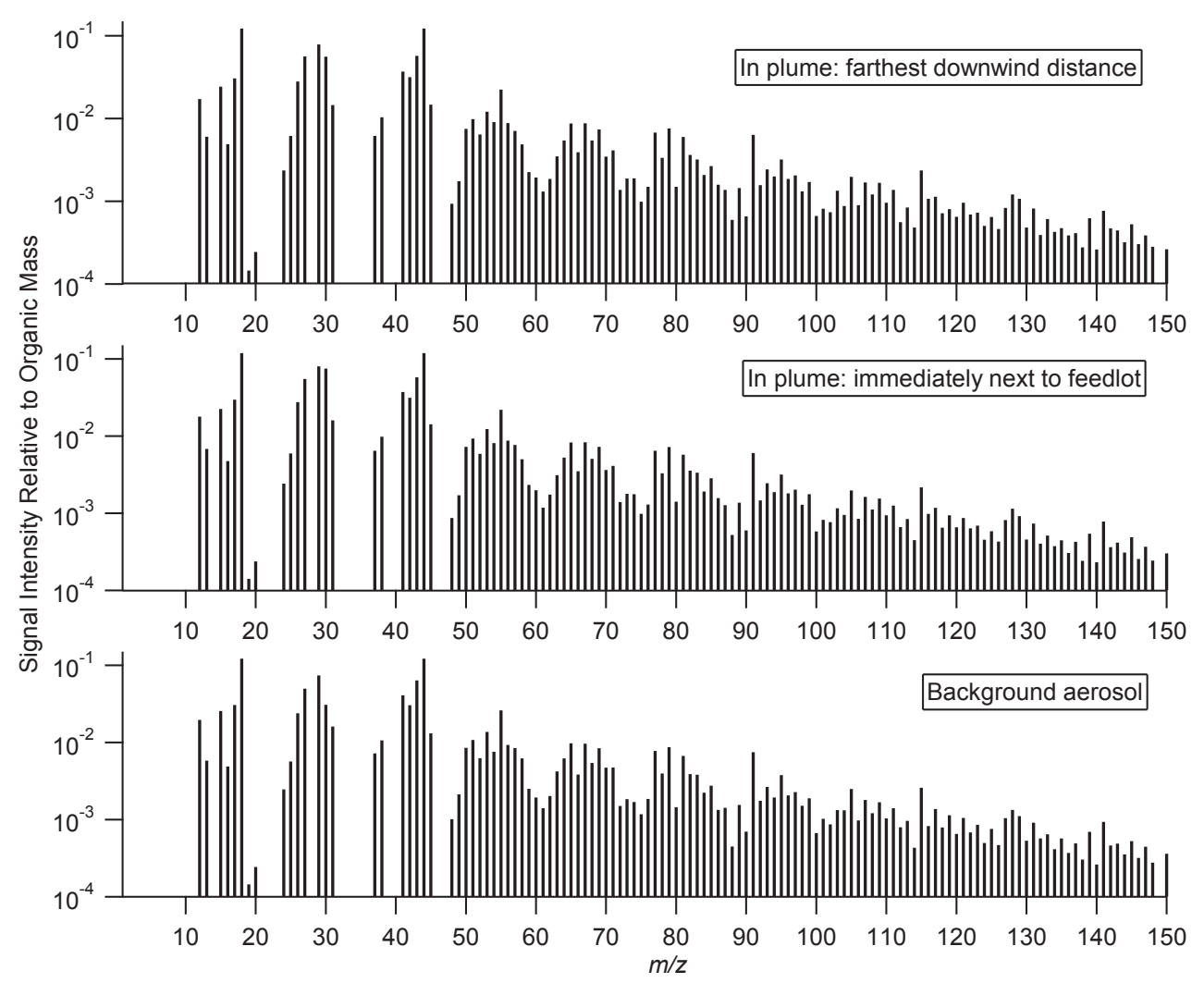

Fig. 10. Aerosol mass spectra from the C-ToF-AMS in the background aerosol and in the plume at various downwind distances from the feedlot for flight B. There is no significant difference in the chemical signature of the aerosol in the three categories shown, with the notable exception of an enhancement in the $m / z, 30$ peak, a common amine marker, at the closest point to the source. The flight A spectra are similar to those presented here.

\subsection{Refractive index}

The background aerosol exhibited a consistent average dryparticle refractive index of $1.54 \pm 0.07$ and $1.54 \pm 0.04$ for flights A and B, respectively (Table 2). Since these values are close to those of ammonium nitrate (1.55) and ammonium sulfate (1.52-1.53) (Weast, 1987; Tang, 1996), which are the dominant inorganic components of the aerosol, assuming a volume-weighted overall refractive index, the organic component refractive index is calculated also to be 1.54. Notably, Zhang et al. (1994) reported a similar refractive index of 1.55 for particulate organic compounds in Grand Canyon aerosol. The overall aerosol refractive indices were slightly lower in the plume, with the lowest values observed closest to the feedlot during the aircraft circling maneuvers $(1.48 \pm 0.09$ and $1.51 \pm 0.01$ for flights $\mathrm{A}$ and $\mathrm{B}$, respectively). Organic species, such as amines, may be responsible for this decrease as the organic mass fraction dominated the total mass; ethylamine and diethylamine have refractive indices of 1.37 and 1.39, respectively (Dean, 1999). Although only two particulate amines were speciated at low concentrations $(<4 \%$ of total mass), other amine compounds may well have existed in the total organic mass with comparable refractive indices.

\subsection{Hygroscopic properties of the aerosol}

\subsubsection{Subsaturated water uptake}

Figures 13 and 14 present the spatial distribution of hygroscopic growth factors at the RHs studied for flights A and $\mathrm{B}$, respectively. Aerosol growth factors ranged from 1.00 to 1.27 at $74 \% \mathrm{RH}, 1.21$ to 1.62 at $85 \% \mathrm{RH}$, and 1.30 to 2.04 at $92 \% \mathrm{RH}$ (Table 2), depending on location, altitude, and proximity to the plume source. For reference, growth factors for pure ammonium nitrate $\left(D_{p, \text { dry }}=150 \mathrm{~nm}\right)$ at RHs of $74 \%, 85 \%$, and $92 \%$ are $1.37,1.60$, and 1.94 , respectively (deliquescence $\mathrm{RH}=61.8 \%$; Brechtel and Kreidenweis, 2000). Growth factors for pure ammonium sulfate $\left(D_{p, \text { dry }}=150 \mathrm{~nm}\right)$ at RHs of $85 \%$ and $92 \%$ are 1.56 and 1.80 , respectively (deliquescence $\mathrm{RH}=79.9 \%$; Brechtel and Kreidenweis, 2000). Overall, the plume aerosol exhibited higher hygroscopic growth factors as compared to the background aerosol. Hygroscopic growth factors in the immediate vicinity of the source were usually between $1.75-1.90$ at $\mathrm{RH}=92 \%$.

Hygroscopic growth factors are now related to the mass fractions of the aerosol components. Figure 15 shows the 

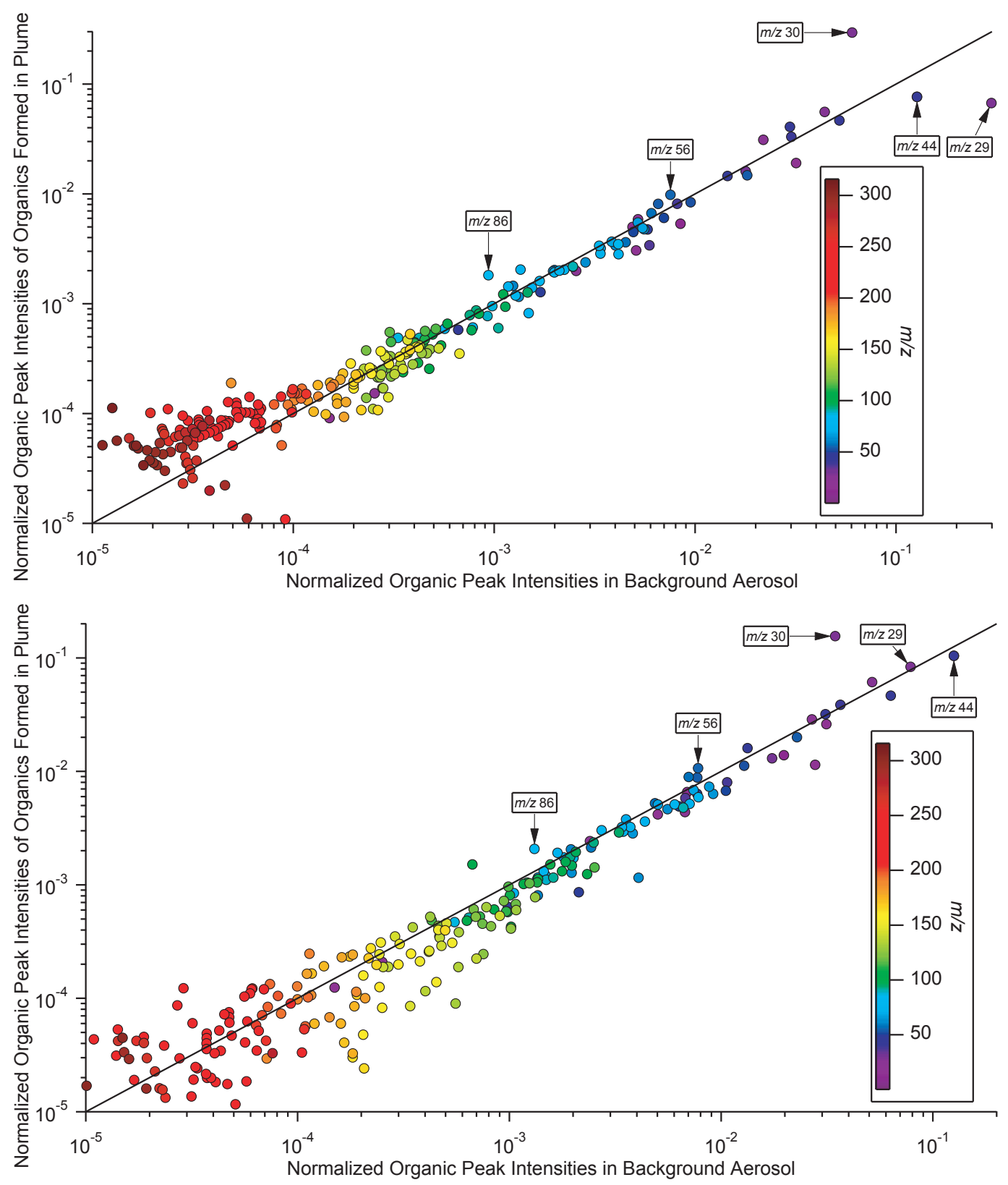

Fig. 11. A comparison of the plume organic mass spectra versus the background aerosol organic mass spectra for flights A (upper panel) and B (lower panel). All non-organic contributions to the mass spectra have been removed by fragmentation calculations described in Sect. 3.3.3. This means that the signal at $\mathrm{m} / \mathrm{z} 30$ represents a fragment of organics, including amines. The data on the y-axis were generated by taking the difference in the organic spectra in the plume and out of the plume. The organic aerosol appears to be very similar except this plot shows that there is an increase in peak intensities at $\mathrm{m} / \mathrm{z}, 30,56$, and 86 , common amine peaks, in the plume. The peak intensity at $m / z$, 44 (and 29 in flight $\mathrm{A}$ ) is greater in the background aerosol spectra indicating increased oxidation out of the plume as compared to inside the plume.

dependence of growth factors at an $\mathrm{RH}$ of $92 \%$ on mass fractions of nitrate and organics measured for flight B. (Similar effects occur at the other RHs.) Increasing growth factors coincide with higher nitrate mass fractions. This effect is most evident during flight $\mathrm{B}$, in terms of slope $(0.31)$ and correlation $\left(r^{2}=0.43\right)$, partly because of the larger range of nitrate mass fractions observed. In addition, growth factors exhibited a negative correlation $\left(r^{2}=0.46\right.$, slope $\left.=-0.28\right)$ with organic mass fractions. Less correlation exists between observed growth factors and mass fractions of ammonium and sulfate $\left(r^{2}<0.21\right)$. The data show that subsaturated hygroscopicity increases as a function of increasing fraction of 

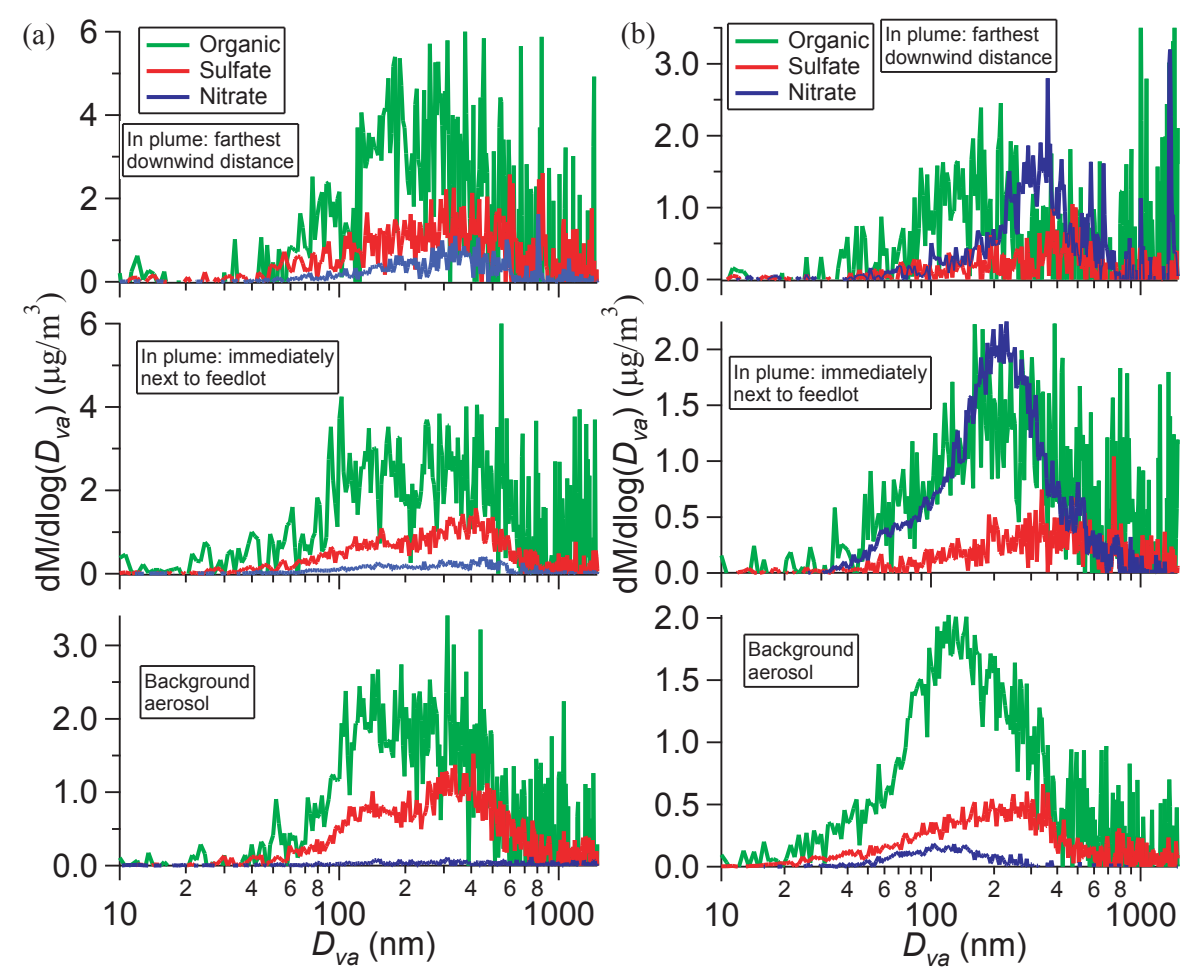

Fig. 12. Speciated size distributions as determined by the C-ToF-AMS for flights A (panel (a)) and B (panel (b)). The $x$-axis is the vacuum aerodynamic diameter. There is evidence of externally mixed aerosols, evident by the independent shifts of various species as a function of increasing plume age. This is clearest in flight B where nitrate is shown to grow in size with plume age with less growth for organics and no growth for sulfate.

Table 2. DASH-SP hygroscopicity and dry particle refractive index data categorized by the time of flight as shown in Fig. 1. Data at $\mathrm{RH}=85 \%$ are not available for flight $\mathrm{A}$.

\begin{tabular}{llllc}
\hline & $G F(74 \%)$ & $G F(85 \%)$ & $G F(92 \%)$ & Dry Refractive Index \\
\hline \multirow{2}{*}{ Flight A } & Valley transit & $1.10 \pm 0.05$ & $1.64 \pm 0.17$ & $1.52 \pm 0.08$ \\
& Circle above plume source & $1.16 \pm 0.12$ & $1.79 \pm 0.22$ & $1.48 \pm 0.08$ \\
& First set of transects (1-4) & $1.07 \pm 0.03$ & $1.55 \pm 0.19$ & $1.52 \pm 0.06$ \\
Transect 1 (plume age=0.3 h) & $1.04 \pm 0.03$ & $1.59 \pm 0.17$ & $1.54 \pm 0.04$ \\
& Transect 2 (plume age=0.5 h) & $1.05 \pm 0.03$ & $1.51 \pm 0.22$ & $1.56 \pm 0.05$ \\
& Transect 3 (plume age=1.1 h) & $1.08 \pm 0.03$ & $1.70 \pm 0.18$ & $1.48 \pm 0.05$ \\
Transect 4 (plume age=1.5 h) & $1.06 \pm 0.01$ & $1.74 \pm 0.08$ & $1.51 \pm 0.01$ \\
Spiral up to 600 m & $1.07 \pm 0.05$ & $1.47 \pm 0.15$ & $1.53 \pm 0.10$ \\
Second set of transects (5-7) & $1.09 \pm 0.04$ & $1.61 \pm 0.13$ & $1.54 \pm 0.05$ \\
Transect 5 (plume age=1.2 h) & $1.06 \pm 0.01$ & & $1.68 \pm 0.06$ & $1.54 \pm 0.05$ \\
Transect 6 (plume age=1.3 h) & $1.12 \pm 0.05$ & & $1.60 \pm 0.08$ & $1.54 \pm 0.05$ \\
Transect 7 (plume age=0.8 h) & $1.12 \pm 0.01$ & $1.69 \pm 0.16$ & $1.54 \pm 0.09$ \\
Spiral down above plume source & $1.33 \pm 0.30$ & & $1.80 \pm 0.19$ & $1.40 \pm 0.10$ \\
Valley transit & $1.06 \pm 0.02$ & & $1.53 \pm 0.15$ & $1.56 \pm 0.05$ \\
\hline Valley transit & $1.03 \pm 0.04$ & $1.35 \pm 0.06$ & $1.49 \pm 0.07$ & $1.55 \pm 0.04$ \\
Circle above plume source & $1.10 \pm 0.07$ & $1.50 \pm 0.10$ & $1.88 \pm 0.22$ & $1.51 \pm 0.01$ \\
First set of transects (plume age $<0.9$ h) & $1.12 \pm 0.05$ & $1.39 \pm 0.08$ & $1.65 \pm 0.20$ & $1.52 \pm 0.01$ \\
Directly in plume (plume age $<0.9 \mathrm{~h}$ ) & $1.15 \pm 0.06$ & $1.44 \pm 0.06$ & $1.86 \pm 0.14$ & $1.52 \pm 0.01$ \\
Spiral up to 400 m & $1.07 \pm 0.04$ & $1.37 \pm 0.06$ & $1.57 \pm 0.07$ & $1.52 \pm 0.01$ \\
Second set of transects (plume age $<0.9 \mathrm{~h}$ ) & $1.08 \pm 0.04$ & $1.39 \pm 0.06$ & $1.65 \pm 0.17$ & $1.53 \pm 0.03$ \\
Directly in plume (plume age $<0.9 \mathrm{~h}$ ) & $1.09 \pm 0.05$ & $1.40 \pm 0.09$ & $1.65 \pm 0.16$ & $1.51 \pm 0.02$ \\
Valley transit & $1.11 \pm 0.04$ & $1.39 \pm 0.08$ & $1.55 \pm 0.11$ & $1.53 \pm 0.05$ \\
\hline
\end{tabular}



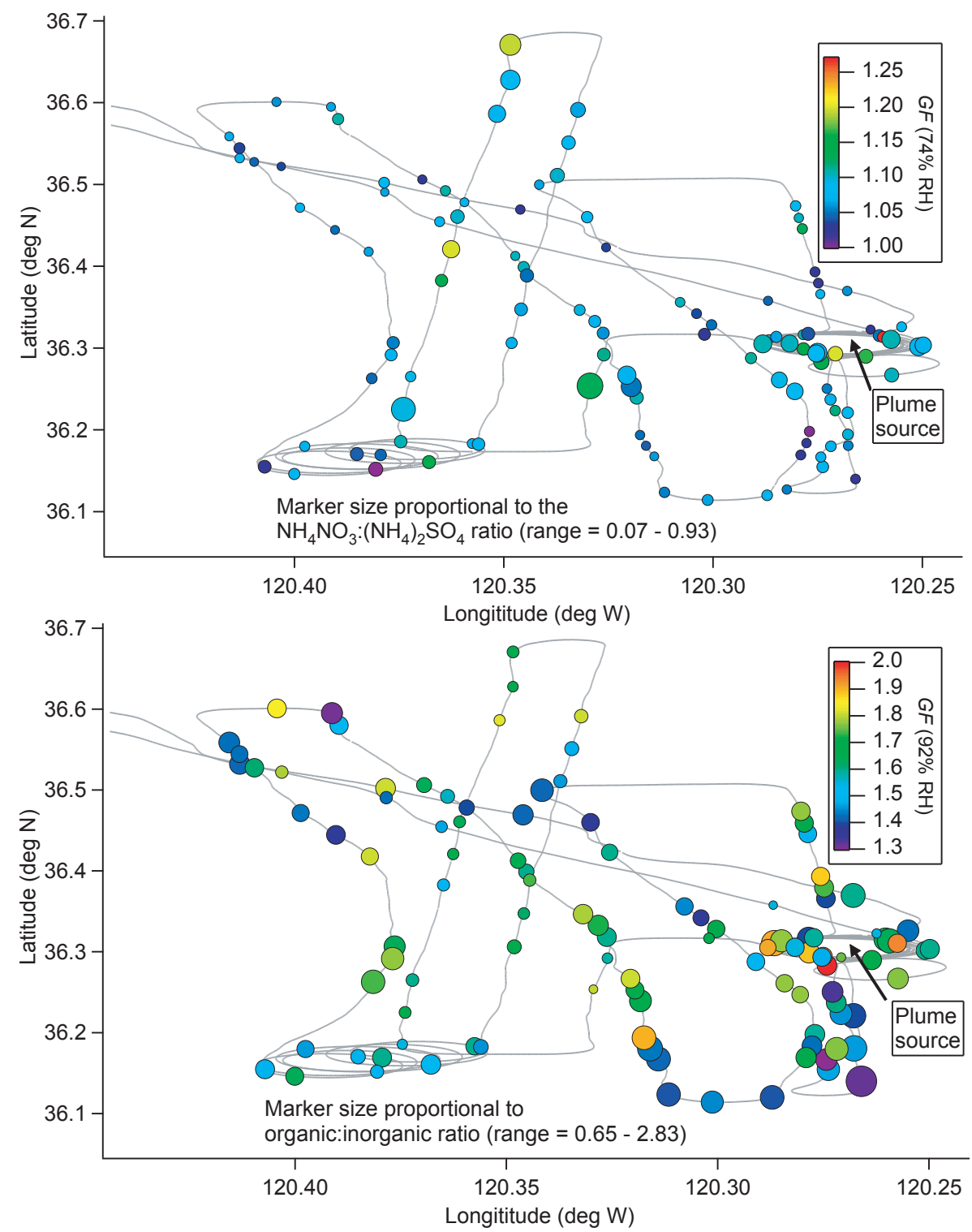

Fig. 13. Growth factor data from flight $A$ at RHs of $74 \%$ (upper panel) and 92\% (lower panel). The markers represent individual DASH-SP scans at dry diameters between 150 and $200 \mathrm{~nm}$. Marker sizes in upper panel are proportional to the ammonium nitrate:ammonium sulfate ratio, while marker sizes in the lower panel are proportional to the organic:inorganic ratio (inorganic=ammonium sulfate+ammonium nitrate).

ammonium nitrate, a highly hygroscopic salt, and decreasing fraction of organics, the growth factor of which will be explored subsequently.

\subsection{2 $\mathrm{CCN}$}

The CCN data acquired are summarized in Table 3 and Fig. 16. Owing to the large number of particles with diameters below about $60 \mathrm{~nm}$, in the background atmosphere as well as in the plume, the activated fractions were quite small. An enhancement in activated fraction was observed in the plume, which is consistent with the observed behavior of subsaturated hygroscopic growth factors.
An important issue is the extent to which aerosol composition influences CCN behavior. This can be manifested in two ways: (1) by affecting the critical supersaturation of the particles; and (2) by influencing the growth rate once the particle activates. Figure 17 shows the normalized activation fraction as a function of hygroscopic growth factor for flight $\mathrm{B}$. The normalization is done by computing the activation fraction assuming the $\mathrm{CCN}$ are composed of pure ammonium sulfate. The normalization removes any variations due to shifts in the shape of the size distribution. It is noted that, in general, higher supersaturations are required to activate particles composed of less hygroscopic material. 

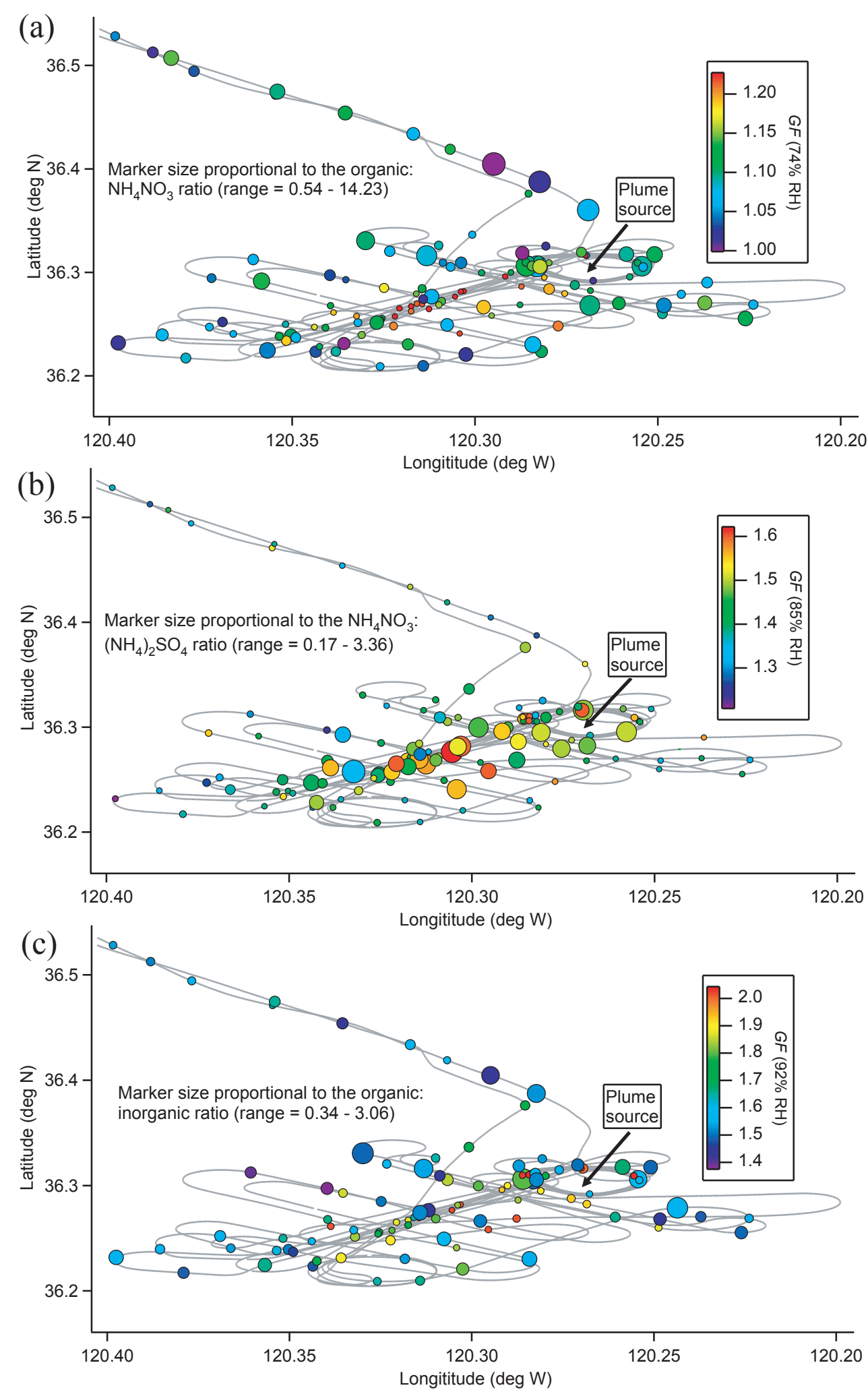

Fig. 14. Growth factor data from flight B at RHs of $74 \%$ (a), $85 \%$ (b), and $92 \%$ (c). The markers represent individual DASH-SP scans at dry diameters between 150 and $200 \mathrm{~nm}$. (a) Marker sizes are proportional to the organic:ammonium nitrate ratio; (b) marker sizes are proportional to the ammonium nitrate:ammonium sulfate ratio; (c) marker sizes are proportional to the organic:inorganic ratio (inorganic=ammonium sulfate+ammonium nitrate). 
Table 3. Summary of CCN data for flights A and B.

\begin{tabular}{|c|c|c|c|c|c|c|c|c|c|c|c|c|}
\hline & & & $\begin{array}{c}\mathrm{CCN} \\
\left(\# / \mathrm{cm}^{3}\right)\end{array}$ & $\begin{array}{l}\text { Activated } \\
\text { fraction }\end{array}$ & $\begin{array}{c}\mathrm{CCN} \\
\left(\# / \mathrm{cm}^{3}\right)\end{array}$ & $\begin{array}{l}\text { Activated } \\
\text { fraction }\end{array}$ & $\begin{array}{c}\mathrm{CCN} \\
\left(\# / \mathrm{cm}^{3}\right)\end{array}$ & $\begin{array}{l}\text { Activated } \\
\text { fraction }\end{array}$ & $\begin{array}{c}\mathrm{CCN} \\
\left(\# / \mathrm{cm}^{3}\right)\end{array}$ & $\begin{array}{l}\text { Activated } \\
\text { fraction }\end{array}$ & $\begin{array}{c}\mathrm{CCN} \\
\left(\# / \mathrm{cm}^{3}\right)\end{array}$ & $\begin{array}{c}\text { Activated } \\
\text { fraction }\end{array}$ \\
\hline & & & \multicolumn{2}{|c|}{$\mathrm{SS} \sim 0.1 \%$} & \multicolumn{2}{|c|}{$\mathrm{SS} \sim 0.2 \%$} & \multicolumn{2}{|c|}{$\mathrm{SS} \sim 0.3 \%$} & \multicolumn{2}{|c|}{$\mathrm{SS} \sim 0.4-0.45 \%$} & \multicolumn{2}{|c|}{$\mathrm{SS} \sim 0.5 \%$} \\
\hline \multirow[t]{5}{*}{ Flight A } & In plume & AVE & 92 & 0.01 & 329 & 0.02 & 1114 & 0.06 & 1882 & 0.08 & 2265 & 0.08 \\
\hline & & ST DEV & 123 & 0.01 & 354 & 0.02 & 628 & 0.05 & 526 & 0.04 & 478 & 0.02 \\
\hline & Out of plume & AVE & 141 & 0.01 & 252 & 0.01 & 1124 & 0.05 & 1641 & 0.06 & 1966 & 0.08 \\
\hline & & ST DEV & 218 & 0.01 & 295 & 0.01 & 561 & 0.03 & 484 & 0.02 & 478 & 0.02 \\
\hline & & & \multicolumn{2}{|c|}{$\mathrm{SS} \sim 0.2 \%$} & \multicolumn{2}{|c|}{$\mathrm{SS} \sim 0.25-0.35 \%$} & \multicolumn{2}{|c|}{$\mathrm{SS} \sim 0.4-045 \%$} & \multicolumn{2}{|c|}{$\mathrm{SS} \sim 0.6 \%$} & & \\
\hline \multirow[t]{4}{*}{ Flight B } & In plume & AVE & 855 & 0.05 & 1246 & 0.07 & 2027 & 0.11 & 2436 & 0.15 & & \\
\hline & & ST DEV & 584 & 0.03 & 713 & 0.04 & 523 & 0.03 & 834 & 0.05 & & \\
\hline & Out of plume & AVE & 707 & 0.04 & 1073 & 0.06 & 1796 & 0.08 & 4168 & 0.14 & & \\
\hline & & ST DEV & 596 & 0.03 & 770 & 0.05 & 768 & 0.03 & 2052 & 0.04 & & \\
\hline
\end{tabular}

Regarding the effect of particle composition on growth rate, consider two particles each having the same critical supersaturation. If the ambient supersaturation exceeds the critical supersaturation, then each particle will activate. The subsequent rate of growth by water condensation depends on the uptake of water molecules. If the two particles have different composition, then the uptake coefficients for water vapor can be different; the particle with the smaller water uptake coefficient will exhibit a slower rate of growth after activation. In a $\mathrm{CCN}$ instrument, like the $\mathrm{CCNc}$ employed here, the more slowly growing particle may not reach its ultimate size before it exits the growth chamber of the instrument and is detected by the OPC. The growth rate of pure ammonium sulfate particles of the same critical supersaturation as that of the particle in question can be taken as the standard against which particle growth rates can be compared. Since an entire distribution of particles enter the $\mathrm{CCNc}$, with different critical supersaturations (as a result of size and composition), the standard used is ammonium sulfate with a critical supersaturation equal to the supersaturation of the instrument. Based on this standard, if all particles grow as quickly as those composed entirely of ammonium sulfate, all particles will have droplet sizes equal to or larger than the standard. Hence, at a given supersaturation, the presence of droplets with a size less than that of the standard indicates retarded growth. We express this effect in terms of the fraction of droplets less than the standard at the supersaturation of the instrument.

Figure 18 shows the C-ToF-AMS - derived ratio of $\mathrm{m} / \mathrm{z}$ $57: 44$ as a function of organic mass fraction. (A larger $\mathrm{m} / \mathrm{z}$ $57: 44$ ratio is correlated with the organic material being less oxidized, and hence more hydrophobic.) The color coding of the data points corresponds to the fraction of droplets that have a size $\left(D_{i}\right)$ less than the ammonium sulfate standard $\left(D_{A S}\right)$, as described above. The size of the symbols reflects the hygroscopic growth factor at $92 \% \mathrm{RH}$. The data indicate that at high organic mass fractions when the particles are composed of less oxidized material, there is a tendency, although weak, towards retardation of growth. The degree of correlation $\left(r^{2}\right)$ between the fraction of droplets
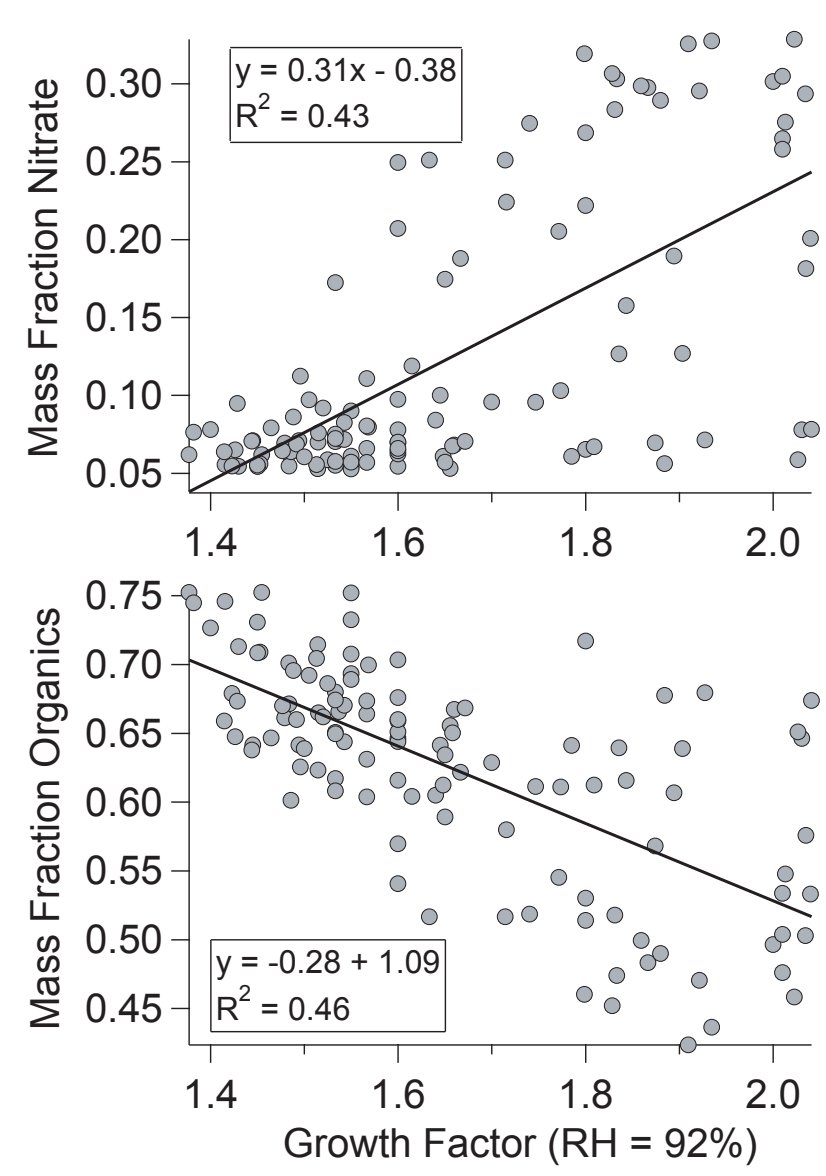

Fig. 15. Relationship between the hygroscopic growth factor at 92\% RH and mass fractions of nitrate and organics during flight B. Less correlation exists between the subsaturated hygroscopic growth factors and the mass fractions of ammonium $\left(r^{2}=0.19\right.$, slope $=0.07)$ and sulfate $\left(r^{2}=0.21\right.$, slope $\left.=-0.10\right)$.

with $\left(D_{i}\right)<\left(D_{A S}\right)$ and various measurements of the organic material are as follows: $m / z$ 57:44 (0.11), organic mass fraction (0.03), product of $m / z \quad 57: 44$ and organic mass fraction 

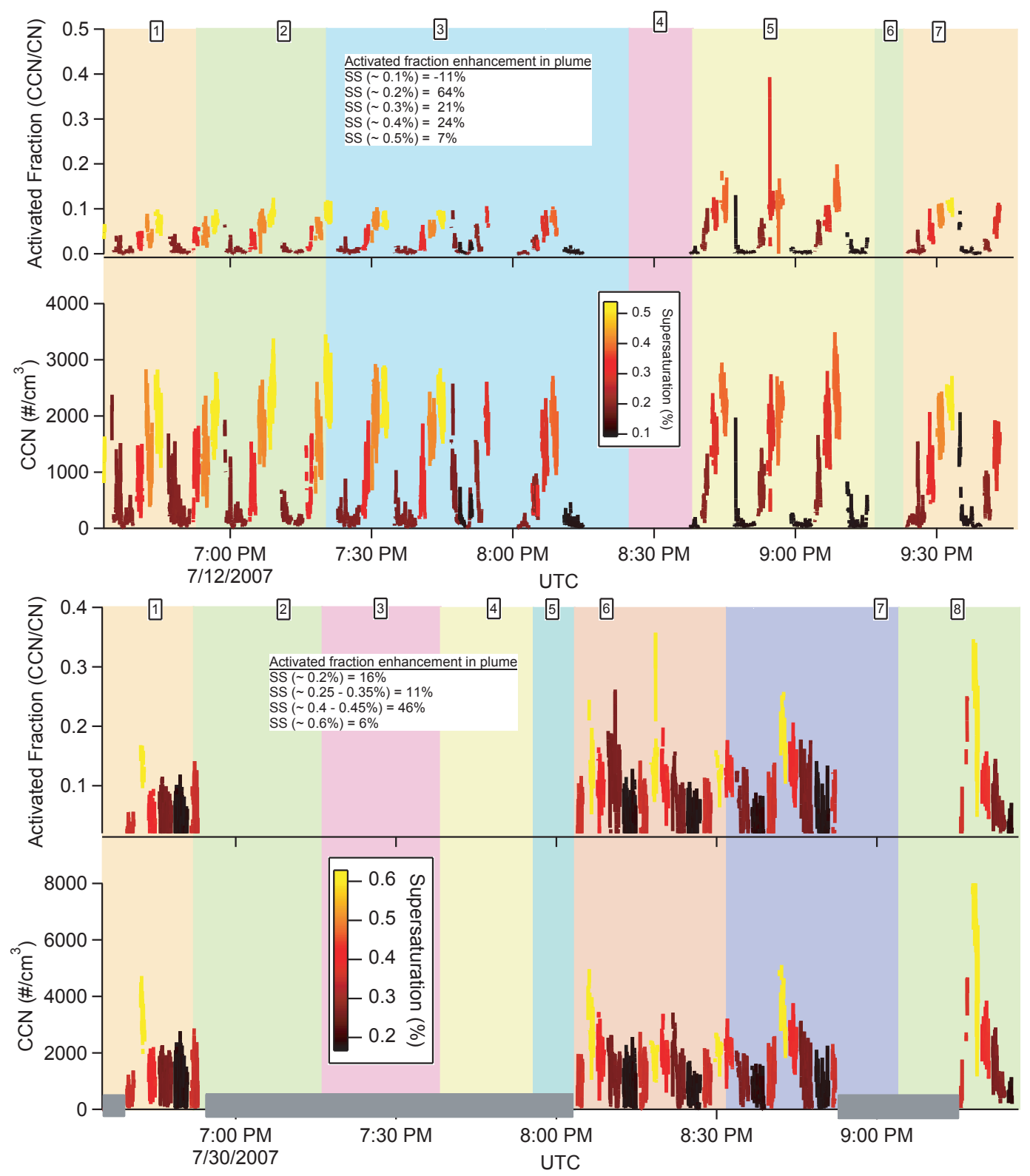

Fig. 16. Time series of activated fraction of aerosol $(\mathrm{CCN} / \mathrm{CN})$, and total $\mathrm{CCN}$ concentration during flights A (upper panel) and B (lower panel). Data points are color-coded with instrument supersaturation. The shaded gray boxes in the lower panel indicate portions of flight B when the $\mathrm{CCNc}$ was operating in an alternative mode and those data are not presented here.

(0.01). The growth factor exhibits a clear anti-correlation with organic mass fraction.

\section{Discussion}

In this section we explore key findings in this study. The observations reveal significant differences in aerosol properties in and out of the plume, and as a function of plume age. Significant enhancements in nitrate, ammonium, and organic levels in the plume were observed; this coincided with an increased potential for water uptake in both the sub- and supersaturated regimes. While trends in the data from the two flights were similar, particle number and mass concentrations were larger in flight A. Explanations for this discrepancy will be pursued.

Owing to the range of organic fractions observed, the present study provides an opportunity to evaluate the sensitivity of mixed inorganic/organic particle hygroscopicity to the organic fraction. Subsaturated hygroscopic growth factors are calculated for the organic fraction based on a closure 


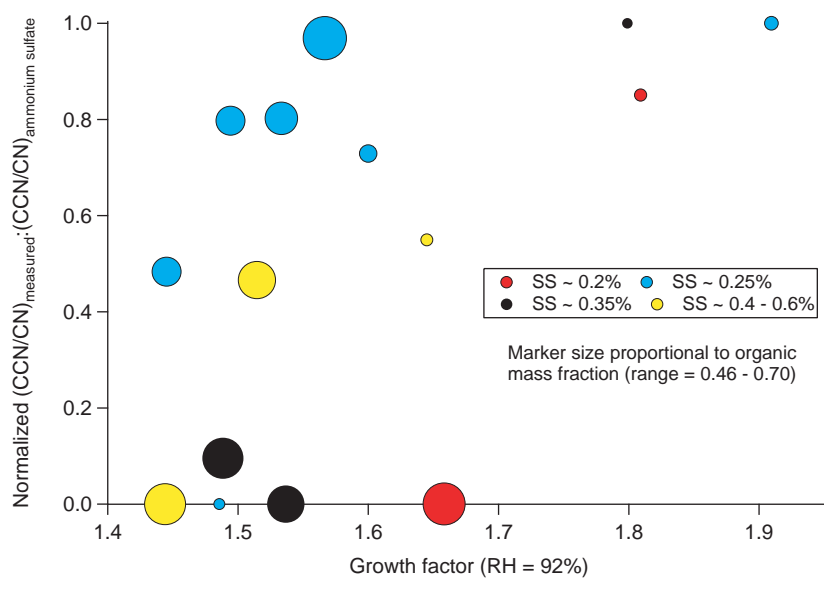

Fig. 17. Normalized $\mathrm{CCN}$ activation ratio, $(\mathrm{CCN} / \mathrm{CN})_{\text {measured }}:(\mathrm{CCN} / \mathrm{CN})_{\text {ammonium sulfate, as a function }}$ of hygroscopic growth factors for flight $\mathrm{B}$. The effects of size distribution and mixing state have been removed from the data and the calculated activation ratio to isolate the impact of composition on the relationship between water uptake in the sub- and supersaturated regimes (see Sect. 3.6.2).

analysis using the Zdanovskii-Stokes Robinson (ZSR) mixing rule. Measurement of $\mathrm{CCN}$ activity in this study also presents an opportunity to assess the consistency of observed supersaturated water uptake with the subsaturated water uptake measurements.

4.1 Enhancements in mass production and water uptake in the plume aerosol

Significant production of ammonium nitrate and organic mass in the plume occurred during both flights. Ammonium nitrate production is expected due to the high ammonia levels and the presumed abundance of nitric acid from the daytime photochemistry. Organic aerosol mass production results from both condensation of semi-volatile organic species and acid-base chemistry of amines, followed by condensation of low-volatility products onto pre-existing aerosols.

Enhanced sub- and supersaturated water uptake coincides with greater fractions of ammonium, nitrate, and amines. Dinar et al. (2008) have shown, for example, that the reactive uptake of ammonia by aerosols containing slightly soluble organics leads to substantial increases in hygroscopic growth and CCN activity. This observation appears to be consistent with the present measurements. Speciated size distributions show that the aerosol is, in part, externally mixed, with different species growing independently during plume aging (Fig. 12). The high organic fractions, particularly during flight A, may have masked the expected and significant growth exhibited by pure ammonium nitrate and ammonium sulfate salts; however, amines, which represent one class of organic species in the plume, are thought to be highly hygroscopic. Aklilu et al. (2006) also suggested that the organic

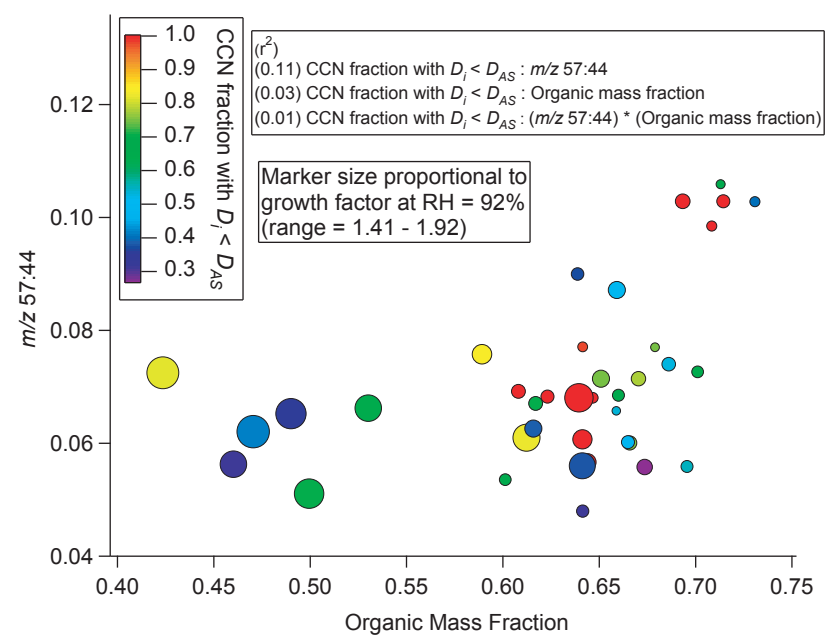

Fig. 18. The relationship between the $m / z$ 57:44 ratio, the organic mass fraction, the CCN fraction with less droplet growth than ammonium sulfate $\left(D_{i}<D_{A S}\right)$, and the hygroscopic growth factor at $\mathrm{RH}=92 \%$. The CCN fraction with $D_{i}<D_{A S}$ is a qualitative measure of kinetic limitations to droplet growth. The majority of the markers representing the lowest values of $D_{i}<D_{A S}$ occur at $\mathrm{m} / z$ 57:44<0.07, while most of the higher values of $D_{i}<D_{A S}$ coincide with the highest organic mass fractions $(>0.6)$. The highest growth factors at $\mathrm{RH}=92 \%$ occur at the lowest organic mass fractions and $\mathrm{m} / \mathrm{z}$ 57/44 ratios.

fraction of the aerosol can suppress the growth normally associated with nitrate based on ambient measurements at two rural, urban-influenced sites.

\subsection{Amines as an atmospheric base}

\subsubsection{Is nitric acid or ammonia the limiting reactant?}

Previous studies of particulate ammonium nitrate formation in the San Joaquin Valley suggest that the limiting reactant is nitric acid because of abundant ammonia emissions (Blanchard et al., 2000; Pun and Seigneur, 1999). During an aircraft study in the San Joaquin Valley in May 2002, Neuman et al. (2003) reported simultaneous nitric acid depletion and aerosol mass enhancements when the aircraft either encountered large ammonia sources or reached lower temperatures at higher altitudes in the boundary layer. Ammonia is emitted from the ground, whereas nitric acid is efficiently produced photochemically throughout the entire boundary layer, especially during the summer in the daytime San Joaquin Valley atmosphere.

Since gas-phase ammonia and nitric acid were not measured in the present study, observed particulate levels of ammonium, nitrate, sulfate, and amines can help determine the limiting reactant in chemical processing inside the plume. Excess nitrate is most abundant within the plume, reaching levels as high as $1.72 \mu \mathrm{g} / \mathrm{m}^{3}$ (flight A) and $0.89 \mu \mathrm{g} / \mathrm{m}^{3}$ (flight B). (As defined in Sect. 2.1, excess nitrate is the amount 
of nitrate remaining after both sulfate and nitrate have been fully neutralized by ammonium.) The greatest excess $n i-$ trate values coincide with relatively lower ambient temperatures, higher altitudes, the presence of diethylamine and ethylamine, and are correlated with amine markers in the C-ToF-AMS spectra $(\mathrm{m} / \mathrm{z}, 56$ and 86) (Figs. 7b, 8b and 9). The background aerosol tends to exhibit excess nitrate values close to zero, indicating that just enough ammonia was present, on average, to neutralize both sulfate and nitrate. The data suggest either of two conclusions: (1) insufficient ammonia was present to neutralize both sulfate and nitrate within the plume, thereby distinguishing ammonia as the limiting reactant; or (2) sufficient ammonia was present, but a significant amount of nitric acid formed salts preferentially with amines rather than ammonia. The detection of amines by the PILS and the large amount of organic mass, with representative amine markers detected by the C-ToF-AMS, suggests that the second explanation may be more plausible. This is a significant finding in the atmosphere that is consistent with laboratory observations made in photooxidation experiments of aliphatic amines (Angelino et al., 2001; Murphy et al., 2007). The affinity of inorganic acids for amines in the presence of ammonia could possibly have greater implications under conditions of lower temperatures and higher RHs due to increased partitioning of both ammonium nitrate and amine salts into the aerosol phase. However, caution must be taken when extrapolating the current results to other atmospheric conditions such as stronger pollution events, especially during winter stagnation events in the San Joaquin Valley, when a great excess of ammonia can exist over nitric acid.

\subsubsection{Sources and character of amines}

The formation of particulate amine salts depends on temperature, the identity and concentrations of the amine and acidic species present, and the concentration of ammonia that competes with amines for the acidic species. Once the particulate amine salts are formed, they may revolatilize, undergo subsequent particle-phase reactions including oxidation, or serve as a site for the condensation of other organic compounds. Chamber experiments performed by Murphy et al. (2007) showed that the dominant formation mechanism for amines is that of acid-base reactions (amine+nitric acid) rather than from photooxidation to form non-salt condensable organics. These experiments showed that nitric acid preferentially reacts with amines, depending on the species, rather than ammonia. It is expected that particulate amines should be prevalent close to the source of amine emissions where gaseous amine concentrations are highest. If the temperature dependence of amine salt equilibria resembles that of ammonium nitrate, then amines should partition more favorably to the aerosol phase at lower temperature (higher altitudes) within the plume. Of the six amines studied by Murphy et al. (2007), diethylamine was shown to have the most favorable equilibrium constant for salt formation in the presence of ammonia, an observation that is consistent with the present field measurements since diethylamine was the most abundant amine detected in the aerosol. The amine salts produced in the laboratory chamber experiments eventually repartitioned back to the gas phase. In the present study, amine concentrations decreased as a function of plume age, as evident in the $m / z, 30$ peak intensity data from the C-ToFAMS (Fig. 10). The decreasing amine levels in the aerosol phase presumably occur because of two reasons: (1) amine concentrations, like those of ammonium and nitrate, decrease due to dilution as a function of plume age; and (2) amines partition back to the gas phase to maintain thermodynamic equilibrium due to the decreasing gas-phase concentrations owing to dilution.

Diethylamine, measured exclusively in the plume, exhibited a strong and positive correlation with nitrate, ammonium, sulfate, and total organics during flight $\mathrm{A}\left(n=8, r^{2}\right.$ : nitrate $=0.65$, ammonium $=0.73$, sulfate $=0.72$, organics $=0.68$ ), but showed a weaker correlation with the same species during flight $\mathrm{B}\left(n=7, r^{2}\right.$ : nitrate $=0.35$, ammonium $=0.04$, sulfate $=0.13$, total organics $=0.40$ ). The positive correlation between diethylamine and nitrate suggests that nitric acid exhibits an affinity for amines as an atmospheric base, even in the presence of ammonia. Diethylamine concentrations correlated more weakly with sulfate than to nitrate during flight $\mathrm{B}$, possibly because nitric acid levels were higher than those of sulfuric acid causing the formation of particulate amines to proceed only through the amine $+\mathrm{HNO}_{3}$ acid-base reaction. When diethylamine was detected, its average mass ratio relative to nitrate was 0.31 (flight A) and 0.36 (flight B); relative to sulfate it was 0.16 (flight $\mathrm{A}$ ) and 0.36 (flight $\mathrm{B}$ ), and relative to ammonium it was 0.31 (flight $\mathrm{A}$ ) and 0.17 (flight B).

\subsubsection{Total amine mass calculations}

One can estimate the total mass of amines present in the plume. This calculation assumes that excess nitrate is in a 1:1 molar ratio with amines. Amine mass is then determined by assuming a representative molecular weight for the amine population. We choose to use methylamine and triethylamine as lower and upper limits, respectively, since these species represent the smallest and largest amines that can be speciated using the PILS-IC technique (Murphy et al., 2007); the molecular weight of the two amines detected in this study, ethylamine and diethylamine, fall within the range of those of methylamine and triethylamine.

On the basis of the molecular weight of methylamine $(31.1 \mathrm{~g} / \mathrm{mol})$, average amine concentrations in the plume are calculated to have been $0.23 \pm 0.13 \mu \mathrm{g} / \mathrm{m}^{3}$ ( $4 \%$ of total organic mass) (flight A) and $0.06 \pm 0.10 \mu \mathrm{g} / \mathrm{m}^{3}$ ( $2 \%$ of total organic mass) (flight $\mathrm{B}$ ), while maximum plume concentrations were $0.86 \mu \mathrm{g} / \mathrm{m}^{3}$ (13\% of total organic mass) (flight A) and $0.44 \mu \mathrm{g} / \mathrm{m}^{3}$ (19\% of total organic mass) (flight 
B). On the basis of the molecular weight of triethylamine $(101.1 \mathrm{~g} / \mathrm{mol})$, average amine concentrations are calculated to have been $0.76 \pm 0.43 \mu \mathrm{g} / \mathrm{m}^{3}$ ( $12 \%$ of total organic mass) (flight A) and $0.20 \pm 0.32 \mu \mathrm{g} / \mathrm{m}^{3}$ (8\% of total organic mass) (flight B), while maximum levels were $2.81 \mu \mathrm{g} / \mathrm{m}^{3}$ (43\% of total organic mass) (flight A) and $1.45 \mu \mathrm{g} / \mathrm{m}^{3}$ (63\% of total organic mass) (flight B). Using the conservative molecular weight of methylamine, amine mass was at least $23 \%$ (flight A) and $14 \%$ (flight B) of ammonium mass in this plume. In addition, speciated amines (ethylamine and diethylamine via the PILS) accounted for at least 25\% (flight A) and $45 \%$ (flight B) of the estimated total amine mass (via the excess nitrate calculation from the $\mathrm{C}-\mathrm{ToF}-\mathrm{AMS}$ ).

\subsection{Degree of oxidation and volatility in the Aerosol}

In the absence of strong signals in the data representing primary particulate emission sources, the submicrometer aerosol in the sampling region is presumed to originate mainly from secondary production. No obvious signs of primary aerosol vehicular emissions existed based on organic markers in the C-ToF-AMS spectra. The ratio of $\mathrm{m} / \mathrm{z}$ 57:44 peak intensities from the C-ToF-AMS can provide some insight into the relative ratio of hydrocarbon-like (HOA) and oxygenated organic (OOA) aerosols (Zhang et al., 2005); $\mathrm{m} / \mathrm{z} 57$ is representative of hydrocarbon-like structures (typically $\mathrm{C}_{4} \mathrm{H}_{9}^{+}$), while $\mathrm{m} / z 44$ (typically $\mathrm{CO}_{2}^{+}$ion) arises only from oxygenated compounds (Alfarra et al., 2004; Cubison et al., 2006). To provide a framework, values of the $\mathrm{m} / \mathrm{z}$ 57:44 ratio have been observed to range between 1-2 at urban sites in Canada and the UK, less than 0.10 at a rural site in Canada, less than 0.10 above the Eastern Pacific Ocean, and between 0.5-2.0 in the exhaust plume of a container ship (http://cires.colorado.edu/jimenez-group/AMSsd/; Alfarra et al., 2004; Ulbrich et al., 2008; Murphy et al., 2008 ${ }^{1}$ ). This ratio was $\sim 0.07 \pm 0.01$ during both flights, with no major changes between the plume and background aerosol (Table 1). Based on this ratio, it appears that the aerosol was highly oxygenated with relatively little hydrocarbon-like organic aerosol (HOA). The ratio of the peak intensity between $\mathrm{m} / \mathrm{z} 44$ and total organics was, on average, $0.10 \pm 0.01$ in the plume aerosol and $0.11 \pm 0.02$ in the background aerosol (Table 1). Peak intensities at $m / z, 44$ (and 29 for flight A) are slightly greater in the background aerosol relative to plume aerosol, indicating a greater degree of oxidation out of the plume than within it (Fig. 11). This is presumably because the background aerosol had aged longer than the fresh emissions in the plume.

\footnotetext{
${ }^{1}$ Murphy, S. M., Agrawal, H., Sorooshian, A., Padró, L. T., Gates, H., Hersey, S., Welch, W. A., Jung, H., Miller, J. W., Cocker III, D. R., Nenes, A., Jonsson, H. H., Flagan, R. C., and Seinfeld, J. H.: Comprehensive simultaneous shipboard and airborne characterization of exhaust from a modern container ship at sea, Environ. Sci. Technol., submitted, 2008.
}

The O:C atomic ratio, which is indicative of the oxidation state of the organic aerosol (OA), can be derived from the ratio of $\mathrm{m} / \mathrm{z}$ 44:OA using the data inventory and methodology presented by Aiken et al. (2008). They determined that $\mathrm{O}: \mathrm{C}$ values range between 0.2 and 0.8 for ambient urban OA, with a diurnal cycle marked by decreases with primary emissions and increases due to photochemical processing and secondary organic aerosol (SOA) production. In the present study, the O:C ratio is typically between 0.45 and 0.50 both in and out of the plume (Table 1); these values are consistent with what would be expected from fresh SOA.

Organic acids represent a pool of organic species that are water-soluble and highly oxidized. In previous aircraft measurements, organic acids $\left(\mathrm{C}_{1}-\mathrm{C}_{9}\right)$ contributed $3.4 \pm 3.7 \%$ to the total PILS mass in an urban atmosphere (Houston, Texas; Sorooshian et al., 2007a) and $3.5 \pm 3.1 \%$ in a marine atmosphere (Eastern Pacific Ocean; Sorooshian et al., 2007b). In the present study, organic acids contributed $2.4 \pm 5.5 \%$ to the total PILS mass, indicating greater variability and a lower average mass fraction of organic acids than seen in the other field data. Gas-particle partitioning of these water-soluble organic species may have been affected by the high ambient temperatures in the present flights. In addition, the relatively low humidities and lack of clouds prevented organic acid production via aqueous-phase processing during the measurement period (Sorooshian et al., 2006b). Assuming that photochemical reactions efficiently take place in the aqueous phase, the possibility also exists that photochemical processing is less effective in the absence of an aqueous medium. Organic acid concentrations were not correlated with ammonium or nitrate, which represent semi-volatile species, during the present flights. The ammonium nitrate levels varied significantly in the plume, but concentrations of the organic acids were relatively stable. Thus, the data do not allow one to conclude whether volatility or RH was the dominant factor controlling organic acid levels.

4.4 Factors fnfluencing aerosol number/mass concentrations

Particle number and mass concentrations were significantly higher during flight $\mathrm{A}$ than in flight $\mathrm{B}$. The presence of nucleation cannot explain this discrepancy, especially in terms of mass concentration (Table 1). The background aerosol concentration in the valley was also higher during flight $\mathrm{A}$ than in flight $\mathrm{B}$. Since there are no significant sources of $\mathrm{SO}_{2}$ in the sampling region, sulfate can be employed as a tracer for accumulated aerosol originating from long-range transport. It should be noted that comparable levels of vehicular emissions could be expected both days as both flights occurred on weekdays. Sulfate concentrations were significantly higher during flight $\mathrm{A}$. The lower temperatures and higher RH during flight A favored partitioning of semi-volatile species, such as ammonium nitrate and organics, to the aerosol phase. The back-trajectory analysis indicates that the sampled air 
mass during flight $\mathrm{A}$ originated three days previously over the Pacific Ocean, while the air sampled in flight B originated in a more polluted inland area (Fig. 5). We conclude that ventilation of the valley during flight $\mathrm{B}$ was more effective than in flight $\mathrm{A}$, reducing aerosol number and mass concentrations.

Over the flight durations, aerosol concentrations were influenced by competition between a growing boundary layer, decreasing RH, and increasing temperatures. Although the aerosol was well-mixed locally in the valley, the timescale for equilibration between the gas and particle phases is shorter than the boundary layer mixing time (Neuman et al., 2003); this may explain fluctuations in the concentrations of aerosol species at various altitudes and distances downwind of the plume source. The topography of the sampling region downwind of the source and general buoyancy in the boundary layer facilitated vertical transport of emissions to lower temperature regions, reducing the dissociation constant of ammonium nitrate aerosol and, presumably, semi-volatile organics (Figs. 7-9). This might explain why the concentrations of organics (diethylamine in particular), nitrate, and ammonium peaked at the highest altitude and farthest downwind distance from the plume source in flight A (Fig. 7 and 9).

4.5 Estimated subsaturated hygroscopic growth factors for the organic fraction

Calculations were carried out to determine the effective growth factor for the organic fraction needed to achieve composition - hygroscopicity closure. Due to its simplicity and frequent application (Cruz and Pandis, 2000; Dick et al., 2000; Choi and Chan, 2002a, 2002b; Prenni et al., 2003; Wise et al., 2003; Clegg et al., 2003; Clegg and Seinfeld, 2004, 2006a, 2006b; Khlystov et al., 2005; Rissler et al., 2005; Aklilu et al., 2006; Svenningsson et al., 2006; Varutbangkul et al., 2006; Gysel et al., 2007; Sjogren et al., 2007; Dinar et al., 2008), the Zdanovskii-Stokes Robinson (ZSR) (Zdanovskii, 1948; Stokes and Robinson, 1966) mixing rule is employed to predict hygroscopic growth factors. This procedure of estimating hygroscopic growth based on specified composition is based on the assumption that water uptake by each individual component of a particle is independent and additive. We use the following form of the ZSR mixing rule (Aklilu et al., 2006; Gysel et al., 2007):

$G F_{\text {mixed }}\left(a_{w}\right) \approx\left(\sum_{i} \epsilon_{i} G F_{i}\left(a_{w}\right)^{3}\right)^{1 / 3}$

where $G F_{\text {mixed }}$ is the hygroscopic growth factor of the mixed particle, $G F_{i}$ is the hygroscopic growth factor of pure compound $i, a_{w}$ is the activity coefficient of water, and $\epsilon_{i}$ is the volume fraction of pure compound $i$ in the dry particle. $a_{w}=\mathrm{RH}$ in Eq. (1) (Seinfeld and Pandis, 2006). Growth factors for the pure inorganic components were obtained from the Aerosol Inorganics Model (AIM; http://mae.ucdavis.edu/ $\sim$ sclegg/aim.html; Clegg et al., 1998). A growth factor of unity is also assumed for EC, as suggested by Aklilu et al. (2006). Bulk composition data is used to calculate volume fractions in Eq. (1). Although there is evidence for externally-mixed particles in the plume (Fig. 12), assuming an internal mixture for the purposes of calculating volume fractions eliminates uncertainties associated with converting vacuum aerodynamic diameters from the C-ToF-AMS to mobility-equivalent diameters between $150-200 \mathrm{~nm}$ for particles of different densities (the measured growth factors are for dry particle mobility-equivalent diameters between 150$200 \mathrm{~nm}$ ). Therefore, the assumption of an internal mixture is not entirely correct but it will provide for a fairly accurate representation of the composition for the majority of the size distribution.

Assuming an internal mixture, calculating the individual volume fractions requires an estimate of the organic density. If it is assumed that the aerosol is composed of ammonium sulfate (AS), ammonium nitrate (AN), organic carbon (OC), and elemental carbon (EC), then total aerosol density can be expressed as:

$\rho=x_{O C} \rho_{O C}+x_{A S} \rho_{A S}+x_{A N} \rho_{A N}+x_{E C} \rho_{E C}$

where $x_{i}$ are mass fractions and $\rho$ is density of the multicomponent particle, as determined by the ratio of the aerosol mass (via the PILS and C-ToF-AMS) to the aerosol volume (via the DMA); in Eq. (2), $\rho_{O C}$ is the unknown quantity that we desire to determine. Elemental carbon was not quantified in the present study; however, based on extensive chemical characterization of San Joaquin Valley $\mathrm{PM}_{2.5}$ by Chow et al. (2006), the mass fraction of EC tends to be $\sim 5-10 \%$ near the present sampling site. In the absence of a quantitative measure of EC, it is assumed that $5 \%$ of the total submicrometer mass is composed of EC. It is assumed for the purpose of this calculation that all of the sulfate is neutralized by ammonium, and the remaining ammonium occurs as ammonium nitrate. Densities of $1.725,1.769$, and $1.9 \mathrm{~g} / \mathrm{cm}^{3}$ are used for AN, AS, and EC respectively. A wide range of densities are reported for EC $(0.625-2.25) \mathrm{g} / \mathrm{cm}^{3}$ (Fuller et al., 1999); here we assume a value of $1.9 \mathrm{~g} / \mathrm{cm}^{3}$, similar to that employed by Dillner et al. (2001). From the mass concentrations and respective densities of AN, AS, OC, and OC, the volume fraction of each component can be calculated.

On average, the in-plume organic growth factors needed to match the data (flight $\mathrm{A} / \mathrm{B})$ are $1.07 / 1.02(74 \% \mathrm{RH})$, NA/1.28 (85\% RH), and 1.49/1.53 (92\% RH) (Fig. 19). The background aerosol organic growth factors (flight $\mathrm{A} / \mathrm{B}$ ) are $1.08 / 1.03$ (74\% RH), NA/1.21 (85\% RH), and 1.29/1.24 $(92 \% \mathrm{RH})$. Flight $\mathrm{B}$ is characterized by a wider range in the mass fractions of organics, thus this flight presents a better indication of trends in organic growth factor with changing mass fractions. During this flight, inferred organic growth factors increase in the plume as a function of decreasing organic fraction. The lowest organic fractions in flight B 


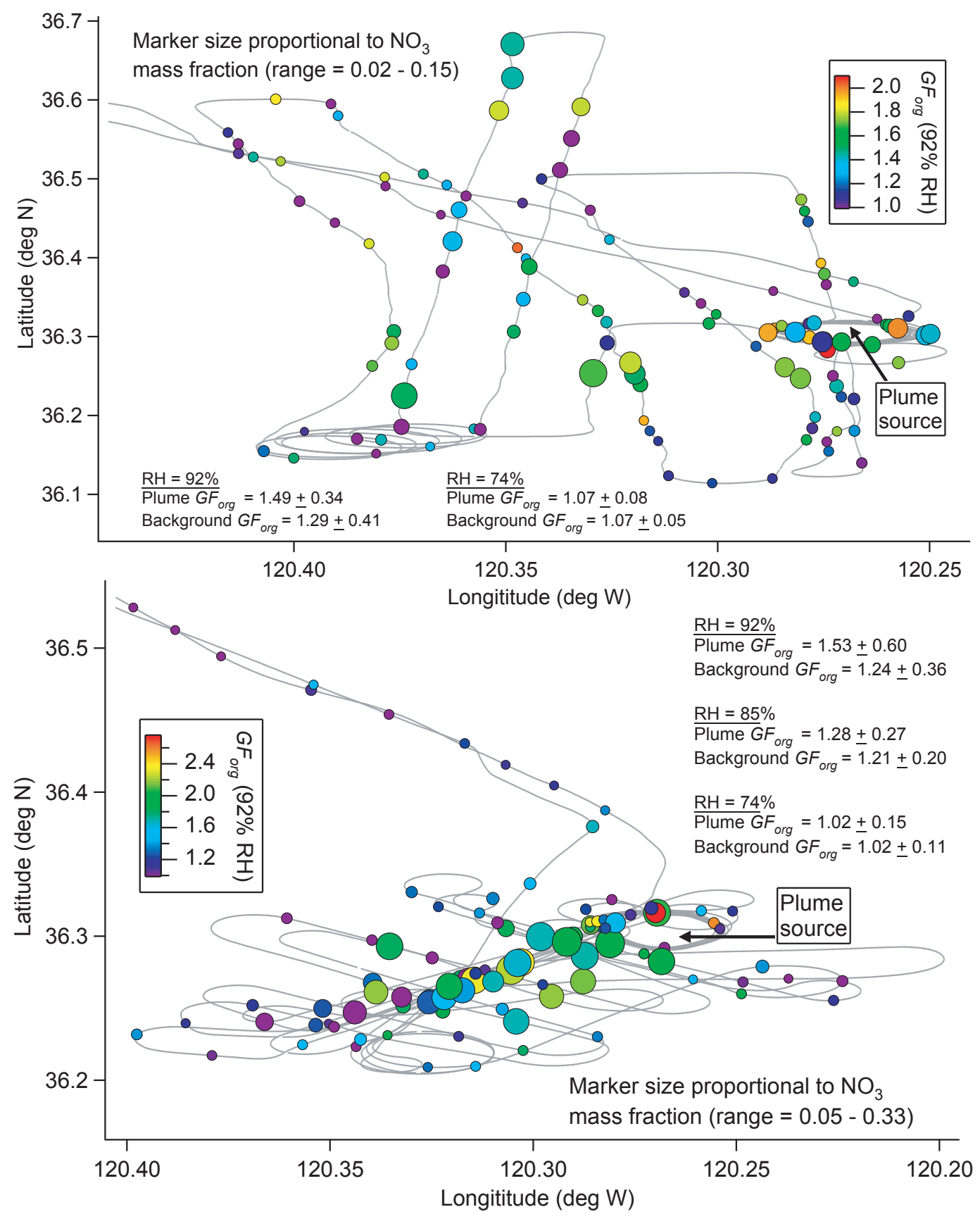

Fig. 19. Spatial distribution of the calculated organic growth factors, using the ZSR mixing rule, for flights A (upper panel) and B (lower panel). Marker sizes are proportional to the mass fraction of nitrate.

coincide with the detection of amines, which likely enhance the hygroscopicity of the organic fraction. There is a significant amount of variation in predicted growth factors at constant organic mass fractions and the absolute values of some of the predicted organic growth factors $(<1$ and $>2)$ are unrealistic. Possible explanations for the unrealistic organic hygroscopic growth factors include: (1) complex particle morphology; (2) complex interactions between the components in the particles leading to non-additive water uptake among the individual components; and (3) errors associated with the calculation of the volume fractions and uncertainties in the measurements. 
Table 4. Summary of $\kappa$ values (Petters and Kreidenweis, 2007) for the total aerosol and the organic component of the aerosol, as derived from subsaturated hygroscopic growth factor data at the respective RHs shown. Data at $\mathrm{RH}=85 \%$ are not available for flight A. The organic $\kappa$ values were calculated using Eq. 7 from Petters and Kreidenweis (2007), CCN-derived values of $\kappa$ for ammonium sulfate and ammonium nitrate from their Table 1 , the total $\kappa$ value calculated at $\mathrm{RH}=92 \%$, and measured volume fractions of ammonium nitrate, ammonium sulfate, and organics.

\begin{tabular}{ccccc}
\hline & \multicolumn{2}{c}{ In plume } & \multicolumn{2}{c}{ Out of plume } \\
\hline & Flight A & Flight B & Flight A & Flight B \\
\hline$\kappa_{\text {total }}(85 \%)$ & NA & $0.40 \pm 0.12$ & NA & $0.33 \pm 0.09$ \\
$\kappa_{\text {total }}(92 \%)$ & $0.36 \pm 0.12$ & $0.44 \pm 0.19$ & $0.29 \pm 0.12$ & $0.28 \pm 0.10$ \\
\hline$\kappa_{\text {organic }}(92 \%)$ & $0.13 \pm 0.08$ & $0.14 \pm 0.15$ & $0.06 \pm 0.07$ & $-0.06 \pm 0.23$ \\
\hline
\end{tabular}

4.6 Relationship between sub- and supersaturated water uptake

One anticipates a direct correspondence between subsaturated hygroscopic behavior and supersaturated $\mathrm{CCN}$ activity. For example, Mochida et al. (2006) explored the relationship between hygroscopicity and CCN activity for urban aerosols using a hygroscopic tandem DMA (HTDMA) coupled in series to a $\mathrm{CCNc}$; enhanced $\mathrm{CCN}$ activity coincided with higher subsaturated growth factors. A similar analysis for the present data (Fig. 17) shows that the normalized CCN activation ratio is generally consistent with water uptake in the subsaturated regime. One interesting feature is the tendency towards relatively higher normalized activation ratios at a supersaturation of $0.25 \%$; we do not have a clear explanation for this other than to point out that more data points were available at this supersaturation, and that temporal and spatial factors during these specific measurements may have played a role. Also, higher activated fractions are consistent with smaller markers, which represent lower organic mass fractions and higher nitrate mass fractions. Enhancements in water uptake for aerosols with lower organic content are likely due to increasing dissolution of water-soluble species, including ammonium nitrate and amine salts, and the possible reduction in surface tension by surface-active species. Organics have previously been shown to influence CCN activity by adding solute and suppressing surface tension (Shulman et al., 1996; Facchini et al., 1999; Feingold and Chuang, 2002; Nenes et al., 2002).

Recent work has shown that kinetic limitations, including surface films and slow dissolution of particulate substances, can suppress droplet growth (Asa-Awuku and Nenes, 2007; Ruehl et al., 2008). With few exceptions including solute being physically "trapped" within some type of waxy material, dissolution kinetics is governed by diffusion of solute from the solid "core" at the center of a droplet to the growing droplet. It has been argued that the latter process is slow enough for compounds with high molecular weights to influence droplet growth kinetics and the Köhler curve (AsaAwuku and Nenes, 2007; Taraniuk et al., 2007; Moore et al., 2008). According to Fig. 18, droplet growth was at times less than that expected for pure ammonium sulfate. In addition, it is shown to some extent that the droplet growth was suppressed for $\mathrm{CCN}$ with relatively greater amounts of hydrophobic organic material. This suggests kinetic limitations may have played a role in suppressing water uptake. This issue will be revisited in subsequent work that will address size-resolved $\mathrm{CCN}$ data from this experiment.

\subsection{Parameterization for sub- and supersaturated water up- take}

To effectively represent the process of water uptake by multicomponent particles in atmospheric models, parameterizations are used. A number of investigators have attempted to introduce parameters to describe water uptake in both the sub- and supersaturated regimes. Expanding upon the earlier work of Fitzgerald et al. (1982), Svenningsson et al. (1992) used a parameter termed to link subsaturated water uptake to cloud and fog activation. Subsequent work introduced closely related parameters for sub- and supersaturated regimes (Kreidenweis et al., 2005; Rissler et al., 2006; Petters and Kreidenweis, 2007). A recently introduced parameter, $\kappa$ (Petters and Kreidenweis, 2007), can be calculated without knowledge of the particle properties such as density, molecular weight, and surface tension.

Kappa can be determined from either CCN activity data or subsaturated hygroscopic growth data. Since the subsaturated DASH-SP growth factors are measured for sizeresolved particles, we use the subsaturated hygroscopicity data to predict the value of $\kappa$ with the following equation (Petters and Kreidenweis, 2007):

$$
\frac{R H}{\exp \left(\frac{A}{D_{d} G F}\right)}=\frac{G F^{3}-1}{G F^{3}-(1-\kappa)} \text {. }
$$

where $\mathrm{A}=\left(4 \sigma_{s / a} M_{w}\right) /\left(R T \rho_{w}\right), D_{d}$ is the dry particle diameter, $G F$ is the growth factor at the corresponding $\mathrm{RH}, M_{w}$ is the molecular weight of water, $\rho_{w}$ is the density of water, $R$ is the universal gas constant, $T$ is temperature, and $\sigma_{s / a}$ is the surface tension at the air/water interface. The water surface tension of $0.072 \mathrm{~J} / \mathrm{m}^{2}$ is assumed, as in the analysis of Petters and Kreidenweis (2007). Briefly, $\kappa$ values of 0.5 to 1.4 represent highly hygroscopic salts such as sodium chloride, values of 0.01 to 0.5 represent slightly to very hygroscopic organics, and a value of 0 represents a non-hygroscopic component (Petters and Kreidenweis, 2007; see Table 1). $\kappa$ values representative of urban, maritime, continental, and remote areas, as derived by Petters and Kreidenweis (2007) using data from previous ambient studies (Fitzgerald and Hoppel, 1982; Hudson and Da, 1996; Dusek et al., 2006), have been reported to range from 0.1 to 0.94 . 
Table 4 summarizes the values of $\kappa$ derived in the present study for both the total aerosol and the organic component of the aerosol. A noticeable enhancement in $\kappa$ occurs within the plume as compared to the background aerosol, which is consistent with the enhancement in subsaturated growth factors. $\kappa$ for the total aerosol is enhanced by between $21 \%$ and $67 \%$ in the plume, with typical values being between $0.36-0.44$. The range of $\kappa$ values, based on DASH-SP data at RHs of $85 \%$ and $92 \%$, is $0.11-0.87$. The correlation between $\kappa$ values and the mass fraction of organics is more pronounced for flight $\mathrm{B} ; \kappa$ increases as the mass fraction of organics decreases and that of nitrate increases. A clear enhancement in the $\kappa$ values for the organic fraction of the aerosol is observed in the plume; typical values are between 0.10 and 0.15 inside the plume and near zero for the background aerosol. Representative $\kappa$ values are assigned to two categories: aerosol from the strong bovine source $(\kappa=0.40)$ and aerosol in an agricultural area $(\kappa=0.30)$. Values of $\kappa$ determined here fall within the range of those derived from previous ambient studies.

\section{Conclusions}

An extensive set of airborne aerosol and meteorological measurements were performed downwind of a massive bovine source in the San Joaquin Valley of California during two flights in July 2007; these include meteorology, particle size distributions, aerosol composition and mixing state, sub- and supersaturated water uptake behavior, aerosol refractive index, and interrelationships between these properties.

Concentrations of total mass, organics, nitrate, and ammonium were elevated within the plume as compared to the background aerosol during both flights. Evidence exists of some degree of external mixing of particles in the plume. Organics constituted the dominant fraction of the total mass in the plume and background aerosol ( $\sim 56-64 \%)$, followed either by sulfate or nitrate, and then ammonium. The O:C atomic ratio of the organic fraction is estimated to have typically been between 0.45 and 0.50 both in and out of the plume. Particulate amines were detected in the plume and are shown to be a significant atmospheric base even in the presence of ammonia; the total amine concentration accounted for at least 23\% (flight A) and 14\% (flight B) of that of ammonium.

The refractive index of the background aerosol in the valley was on average 1.54, but reductions were observed in the plume, especially in the immediate vicinity of the plume source (flight A $\sim 1.48$; flight $\mathrm{B} \sim 1.51$ ). Measurements indicate that increasing uptake of ammonia by aerosols, in the form of ammonium nitrate and ammonium sulfate, relative to the organic fraction, results in an enhancement in particle water uptake and a reduction in refractive index. Amine salts are also hypothesized to have contributed to significant hygroscopic growth in the plume. Hygroscopic growth factors

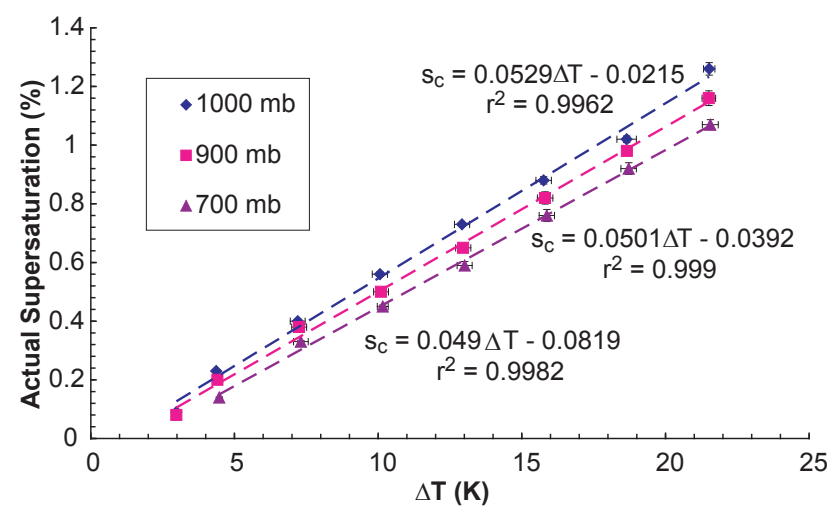

Fig. A1. Critical supersaturation versus delta $T$ calibration for ammonium sulfate aerosol. Calibration was performed at $500 \mathrm{~cm}^{3} / \mathrm{min}$ at 700,900 , and $1000 \mathrm{mb}$.

in the immediate vicinity of the source were generally between $1.75-1.90$ at RH=92\%. Estimated hygroscopic growth factors $(\mathrm{RH}=92 \%)$ for the organic fraction on average were $1.49-1.53$ in the plume and 1.24-1.29 in the background aerosol. Kinetic limitations associated with hydrophobic organic species may have possibly suppressed droplet growth, but the tendency is shown to be weak in this study. After removing effects associated with size distribution and mixing state, enhanced $\mathrm{CCN}$ activated fractions were generally observed as a function of increasing subsaturated growth factors, with the highest activated fractions being consistent with the lowest organic mass fractions. Representative values (Petters and Kreidenweis, 2007) are assigned to two categories: aerosol from the bovine source $(\kappa=0.40)$ and aerosol in an agricultural area $(\kappa=0.30)$. There was a clear enhancement in the values of $\kappa$ representing the organic fraction of the aerosol within the plume, with average values of 0.13 and 0.14 for the two flights.

\section{Appendix A}

This appendix details the calibration procedure for the CCNc. The instrument used in this study was calibrated using ammonium sulfate particles classified with a DMA as follows. An aqueous solution of ammonium sulfate was atomized via a collision-type atomizer operated at $4 \mathrm{psig}$. The droplet stream was passed through multiple diffusional driers (operating at $5-10 \% \mathrm{RH}$ ), resulting in a polydisperse dry aerosol (with modal diameter $\sim 50 \mathrm{~nm}$ ), which was sent through a DMA (Model 3081L, TSI Inc.) operated with a sheath-to-aerosol flow ratio of 10:1. The classified aerosol stream was then sent to a CPC (Model 3010, TSI Inc.) and the Continuous-flow Streamwise Thermal Gradient Chamber (CFSTGC) (operated at constant flow rate, temperature gradient, and pressure) to measure the total aerosol concentration and the total activated particles, respectively. The level of supersaturation in the instrument is determined from the 


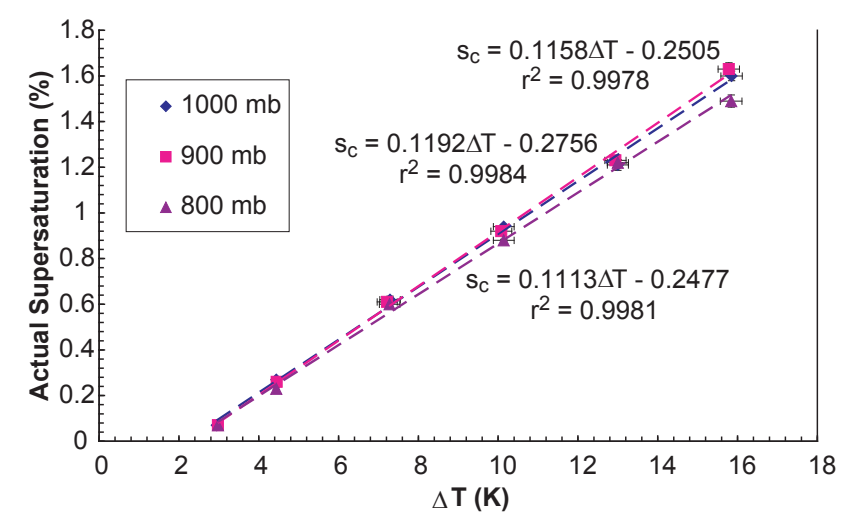

Fig. A2. Critical supersaturation versus delta $T$ calibration for ammonium sulfate aerosol. Calibration was performed at $1000 \mathrm{~cm}^{3} / \mathrm{min}$ at 800,900 , and $1000 \mathrm{mb}$.

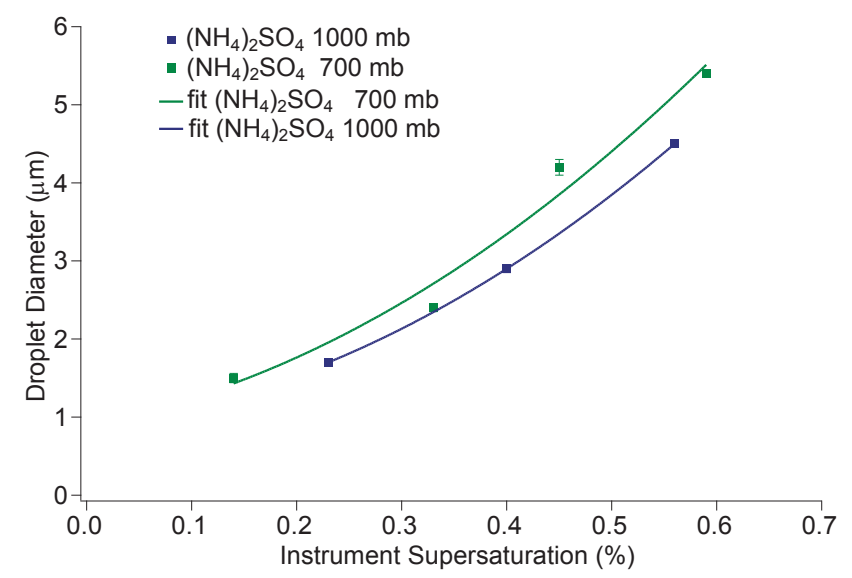

Fig. A3. Growth kinetics plots for aerosol ammonium sulfate aerosol. Calibration was performed at $500 \mathrm{~cm}^{3} / \mathrm{min}$ at 700 and $1000 \mathrm{mb}$.

minimum dry particle diameter, $D_{p 50}$, that activates in the instrument, found by plotting the ratio of $\mathrm{CCN}$ to $\mathrm{CN}$ concentration as a function of mobility particle diameter. A sigmoidal fit to the data (neglecting the effects of multiple particle charging, which is minor for the aerosol used) then determines $D_{p 50}$ as the dry diameter for which $\mathrm{CCN} / \mathrm{CN}=0.50$. The instrument supersaturation is related to $D_{p 50}$ by applying Köhler theory assuming ammonium sulfate has a density of $1760 \mathrm{~kg} / \mathrm{m}^{3}$, surface tension of water, molar mass of $0.132 \mathrm{~kg} / \mathrm{mol}$, and an effective van't Hoff factor of 2.5 . The standard deviation in the supersaturation was determined from the standard deviation observed in the $D_{p 50}$. The error bars in the temperature difference are $1 \sigma$ of the observed variation during the calibrations. Droplet diameter of activated $\mathrm{CCN}$ at the exit of the growth column is also measured; in this study, the growth rate of ammonium sulfate particles is characterized by the average size of droplets formed from particles with dry diameter equal to $D_{p 50}$.

The instrument was calibrated numerous times throughout the study for supersaturations ranging from 0.1 to $1.4 \% \mathrm{SS}$,

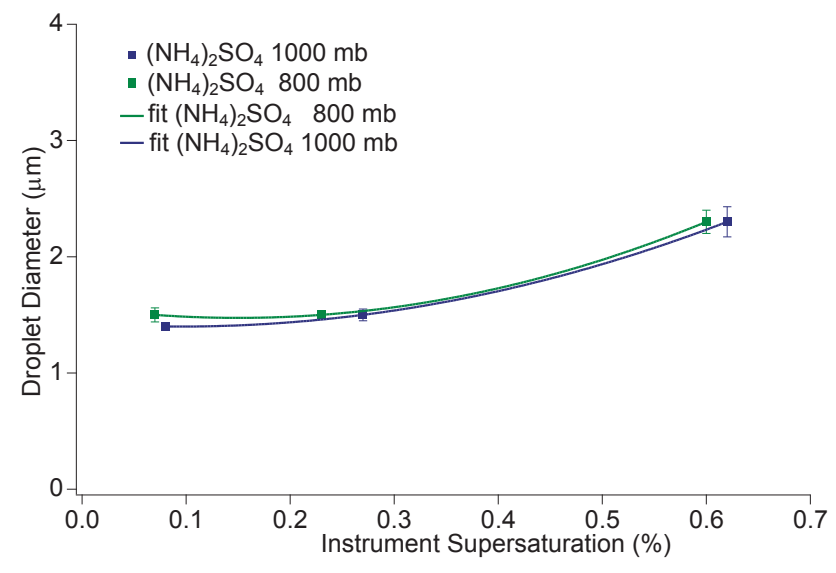

Fig. A4. Growth kinetics plots for aerosol ammonium sulfate aerosol. Calibration was performed at $1000 \mathrm{~cm}^{3} / \mathrm{min}$ at 800 and $1000 \mathrm{mb}$.

for pressures between 700 and $1000 \mathrm{mb}$, and for flow rates ranging between 500 and $1000 \mathrm{~cm}^{3} / \mathrm{min}$. The resulting calibration curves are presented in Figs. A1 and A2. The average size of activated droplets, together with $1 \sigma$ error bars, are shown in Figs. A3 and A4.

The instrument was not operated at constant pressure during flights; instead, the pressure was allowed to vary with altitude. As a result, some transition time is required for the instrument supersaturation to adjust every time altitude changes; the data used in the closure study was filtered for transients resulting from changes in instrument pressure and temperature gradient. The calibration curves are then interpolated with respect to temperature gradient and pressure to determine the in-flight supersaturation.

Acknowledgements. This work was supported, in part, by NOAA grant NA06OAR4310082. A. N. acknowledges support from an NSF CAREER award, NOAA, and NASA. L. T. P. acknowledges support from a NASA Earth System Science Fellowship. The authors gratefully acknowledge the NOAA Air Resources Laboratory (ARL) for provision of the HYSPLIT transport and dispersion model.

Edited by: V. F. McNeill

\section{References}

Abalos, M., Bayona, J. M., and Ventura, F.: Development of a solid-phase microextraction GC-NPD procedure for the determination of free volatile amines in wastewater and sewage-polluted waters, Anal. Chem., 71, 3531-3537, 1999.

Aiken, A. C., Decarlo, P. F., Kroll, J. H., Worsnop, D. R., Huffman, J. A., Docherty, K. S., Ulbrich, I. M., Mohr, C., Kimmel, J. R., Sueper, D., Sun, Y., Zhang, Q., Trimborn, A., Northway, M., Ziemann, P. J., Canagaratna, M. R., Onasch, T. B., Alfarra, M. R., Prevot, A. S. H., Dommen, J., Duplissy, J., Metzger, A., Baltensperger, U., and Jimenez, J. L.: O/C and OM/OC ratios of primary, secondary, and ambient organic aerosols with 
high-resolution time-of-flight aerosol mass spectrometry, Environ. Sci. Technol., 42, 4478-4485, 2008.

Aklilu, Y., Mozurkewich, M., Prenni, A. J., Kreidenweis, S. M., Alfarra, M. R., Allan, J. D., Anlauf, K., Brook, J., Leaitch, W. R., Sharma, S., Boudries, H., and Worsnop, D. R.: Hygroscopicity of particles at two rural, urban influenced sites during Pacific 2001: Comparison with estimates of water uptake from particle composition, Atmos. Environ., 40, 2650-2661, 2006.

Alfarra, M. R., Coe, H., Allan, J. D., Bower, K. N., Boudries, H., Canagaratna, M. R., Jimenez, J. L., Jayne, J. T., Garforth, A. A., Li, S. M., and Worsnop, D. R.: Characterization of urban and rural organic particulate in the lower Fraser valley using two aerodyne aerosol mass spectrometers, Atmos. Environ., 38, 57455758, 2004.

Allan, J. D., Delia, A. E., Coe, H., Bower, K. N., Alfarra, M. R., Jimenez, J. L., Middlebrook, A. M., Drewnick, F., Onasch, T. B., Canagaratna, M. R., Jayne, J. T., and Worsnop, D. R.: A generalised method for the extraction of chemically resolved mass spectra from aerodyne aerosol mass spectrometer data, J. Aerosol Sci., 35, 909-922, 2004.

Anderson, N., Strader, R., and Davidson, C.: Airborne reduced nitrogen: ammonia emissions from agriculture and other sources, Environ. Int., 29, 277-286, 2003.

Angelino, S., Suess, D. T., and Prather, K. A.: Formation of aerosol particles from reactions of secondary and tertiary alkylamines: Characterization by aerosol time-of-flight mass spectrometry, Environ. Sci. Technol., 35, 3130-3138, 2001.

Apsimon, H. M., Kruse, M., and Bell, J. N. B.: Ammonia emissions and their role in acid deposition, Atmos. Environ., 21, 19391946, 1987.

Asa-Awuku, A. and Nenes, A.: Effect of solute dissolution kinetics on cloud droplet formation: Extended Kohler theory, J. Geophys. Res., 112, D22201, doi:10.1029/2005JD006934, 2007.

Asman, W. A. H. and Janssen, A. J.: A long-range transport model for ammonia and ammonium for Europe, Atmos. Environ., 21, 2099-2119, 1987.

Battye, W., Aneja, V. P., and Roelle, P. A.: Evaluation and improvement of ammonia emissions inventories, Atmos. Environ., 37, 3873-3883, 2003.

Beddows, D. C. S., Donovan, R. J., Harrison, R. M., Heal, M. R., Kinnersley, R. P., King, M. D., Nicholson, D. H., and Thompson, K. C.: Correlations in the chemical composition of rural background atmospheric aerosol in the UK determined in real time using time-of-flight mass spectrometry, J. Environ. Monitor., 6, 124-133, 2004.

Blanchard, C. L., Roth, P. M., Tanenbaum, S. J., Ziman, S. D., and Seinfeld, J. H.: The use of ambient measurements to identify which precursor species limit aerosol nitrate formation, J. Air Waste Manage., 50, 2073-2084, 2000.

Brechtel, F. J. and Kreidenweis, S. M.: Predicting particle critical supersaturation from hygroscopic growth measurements in the humidified TDMA. part I: Theory and sensitivity studies, J. Atmos. Sci., 57, 1854-1871, 2000.

Cadle, S. H. and Mulawa, P. A.: Low-molecular weight aliphaticamines in exhaust from catalyst-equipped cars, Environ. Sci. Technol., 14, 718-723, 1980.

Choi, M. Y. and Chan, C. K.: The effects of organic species on the hygroscopic behaviors of inorganic aerosols, Environ. Sci. Technol., 36, 2422-2428, 2002a.
Choi, M. Y. and Chan, C. K.: Continuous measurements of the water activities of aqueous droplets of water-soluble organic compounds, J. Phys. Chem. A, 106, 4566-4572, 2002 b.

Chow, J. C., Watson, J. G., Lu, Z. Q., Lowenthal, D. H., Frazier, C. A., Solomon, P. A., Thuillier, R. H., and Magliano, K.: Descriptive analysis of $\mathrm{PM}(2.5)$ and $\mathrm{PM}(10)$ at regionally representative locations during SJVAQS/AUSPEX, Atmos. Environ., 30, 2079-2112, 1996.

Chow, J. C., Chen, L. W. A., Watson, J. G., Lowenthal, D. H., Magliano, K. A., Turkiewicz, K., and Lehrman, D. E.: PM2.5 chemical composition and spatiotemporal variability during the California Regional PM10/PM2.5 Air Quality Study (CRPAQS), J. Geophys. Res., 111, D10S04, doi:10.1029/2005JD006457, 2006.

Chuang, P. Y.: Measurement of the timescale of hygroscopic growth for atmospheric aerosols, J. Geophys. Res., 108, 4282, doi:10.1029/2002JD002757, 2003.

Clegg, S. L., Brimblecombe, P., and Wexler, A. S.: Thermodynamic model of the system H+-NH4+-Na+-SO42-NO3-ClH2O at 298.15 K, J. Phys. Chem. A, 102, 2155-2171, 1998.

Clegg, S. L., Seinfeld, J. H., and Edney, E. O.: Thermodynamic modelling of aqueous aerosols containing electrolytes and dissolved organic compounds. II. An extended Zdanovskii-StokesRobinson approach, J. Aerosol Sci., 34, 667-690, 2003.

Clegg, S. L. and Seinfeld, J. H.: Improvement of the ZdanovskiiStokes-Robinson model for mixtures containing solutes of different charge types, J. Phys. Chem. A, 108, 1008-1017, 2004.

Clegg, S. L. and Seinfeld, J. H.: Thermodynamic models of aqueous solutions containing inorganic electrolytes and dicarboxylic acids at $298.15 \mathrm{~K}$. 1 . The acids as nondissociating components, J. Phys. Chem. A, 110, 5692-5717, 2006a.

Clegg, S. L. and Seinfeld, J. H.: Thermodynamic models of aqueous solutions containing inorganic electrolytes and dicarboxylic acids at 298.15 K. 2. Systems including dissociation equilibria, J. Phys. Chem. A, 110, 5718-5734, 2006b.

Cruz, C. N. and Pandis, S. N.: Deliquescence and hygroscopic growth of mixed inorganic-organic atmospheric aerosol, Environ. Sci. Technol., 34, 4313-4319, 2000.

Cubison, M. J., Alfarra, M. R., Allan, J., Bower, K. N., Coe, H., McFiggans, G. B., Whitehead, J. D., Williams, P. I., Zhang, Q., Jimenez, J. L., Hopkins, J., and Lee, J.: The characterisation of pollution aerosol in a changing photochemical environment, Atmos. Chem. Phys., 6, 5573-5588, 2006

Dean, J. A.: Lange's Handbook of Chemistry, Fifteenth Edition, McGraw-Hill, 1999.

Denkenberger, K. A., Moffet, R. C., Holecek, J. C., Rebotier, T. P., and Prather, K. A.: Real-time, single-particle measurements of oligomers in aged ambient aerosol particles, Environ. Sci. Technol., 41, 5439-5446, 2007.

Dick, W. D., Saxena, P., and McMurry, P. H.: Estimation of water uptake by organic compounds in submicron aerosols measured during the Southeastern Aerosol and Visibility Study, J. Geophys. Res., 105, 1471-1479, 2000.

Dillner, A. M., Stein, C., Larson, S. M., and Hitzenberger, R.: Measuring the mass extinction efficiency of elemental carbon in rural aerosol, Aerosol Sci. Tech., 35, 1009-1021, 2001.

Dinar, E., Anttila, T., and Rudich, Y.: CCN activity and hygroscopic growth of organic aerosols following reactive uptake of ammonia, Environ. Sci. Technol., 42, 793-799, 2008. 
Doyle, G. J., Tuazon, E. C., Graham, R. A., Mischke, T. M., Winer, A. M., and Pitts, J. N.: Simultaneous concentrations of ammonia and nitric-acid in a polluted atmosphere and their equilibrium relationship to particulate ammonium-nitrate, Environ. Sci. Technol., 13, 1416-1419, 1979.

Draxler, R. R. and Rolph, G. D.: HYSPLIT (HYbrid Single-Particle Lagrangian Integrated Trajectory) Model access via NOAA ARL READY Website (http://www.arl.noaa.gov/ready/hysplit4.html), NOAA Air Resources Laboratory, Silver Spring, MD, 2003.

Drewnick, F., Hings, S. S., DeCarlo, P., Jayne, J. T., Gonin, M., Fuhrer, K., Weimer, S., Jimenez, J. L., Demerjian, K. L., Borrmann, S., and Worsnop, D. R.: A new time-of-flight aerosol mass spectrometer (tof-ams) - instrument description and first field deployment, Aerosol Sci. Tech., 39, 637-658, 2005.

Dusek, U., Frank, G. P., Hildebrandt, L., Curtius, J., Schneider, J., Walter, S., Chand, D., Drewnick, F., Hings, S., Jung, D., Borrmann, S., and Andreae, M. O.: Size matters more than chemistry for cloud-nucleating ability of aerosol particles, Science, 312, 1375-1378, 2006.

Edgerton, E. S., Saylor, R. D., Hartsell, B. E., Jansen, J. J., and Hansen, D. A.: Ammonia and ammonium measurements from the southeastern United States, Atmos. Environ., 41, 3339-3351, 2007

Facchini, M. C., Mircea, M., Fuzzi, S., and Charlson, R. J.: Cloud albedo enhancement by surface-active organic solutes in growing droplets, Nature, 401, 257-259, 1999.

Feingold, G. and Chuang, P. Y.: Analysis of the influence of filmforming compounds on droplet growth: Implications for cloud microphysical processes and climate, J. Atmos. Sci., 59, 20062018, 2002.

Fitzgerald, J. W., Hoppel, W. A., and Vietti, M. A.: The size and scattering coefficient of urban aerosol-particles at Washington, DC as a function of relative-humidity, J. Atmos. Sci., 39, 18381852, 1982.

Fitzgerald, J. W. and Hoppel, W. A.: Measurement of the relationship between the dry size and critical supersaturation of natural aerosol particles, J. Hung. Meteorol. Serv., 86, 242-248, 1982.

Fridlind, A. M. and Jacobson, M. Z.: A study of gas-aerosol equilibrium and aerosol $\mathrm{pH}$ in the remote marine boundary layer during the First Aerosol Characterization Experiment (ACE 1), J. Geophys. Res., 105, 17 325-17 340, 2000.

Fridlind, A. M., Jacobson, M. Z., Kerminen, V. M., Hillamo, R. E., Ricard, V., and Jaffrezo, J. L.: Analysis of gas-aerosol partitioning in the Arctic: Comparison of size-resolved equilibrium model results with field data, J. Geophys. Res., 105, 1989119903, 2000.

Fuller, K. A., Malm, W. C., and Kreidenweis, S. M.: Effects of mixing on extinction by carbonaceous particles, J. Geophys. Res., 104, 15 941-15 954, 1999.

Gerber, H. E., Hoppel, W. A., and Wojciechowski, T. A.: Experimental verification of the theoretical relationship between size and critical supersaturation of salt nuclei, J. Atmos. Sci., 34, 1836-1841, 1977.

Glagolenko, S. and Phares, D. J.: Single-particle analysis of ultrafine aerosol in College Station, Texas, J. Geophys. Res., 109, D18205, doi:10.1029/2004JD004621, 2004.

Gorzelska, K., Talbot, R. W., Klemm, K., Lefer, B., Klemm, O., Gregory, G. L., Anderson, B., and Barrie, L. A.: Chemicalcomposition of the atmospheric aerosol in the troposphere over the Hudson-Bay Lowlands and Quebec-Labrador Regions of Canada, J. Geophys. Res., 99, 1763-1779, 1994.

Gysel, M., Crosier, J., Topping, D. O., Whitehead, J. D., Bower, K. N., Cubison, M. J., Williams, P. I., Flynn, M. J., McFiggans, G. B., and Coe, H.: Closure study between chemical composition and hygroscopic growth of aerosol particles during TORCH2, Atmos. Chem. Phys., 7, 6131-6144, 2007, http://www.atmos-chem-phys.net/7/6131/2007/.

Hegg, D. A., Covert, D. S., Jonsson, H., and Covert, P. A.: Determination of the transmission efficiency of an aircraft aerosol inlet, Aerosol Sci. Tech., 39, 966-971, 2005.

Hildemann, L. M., Russell, A. G., and Cass, G. R.: Ammonia and nitric-acid concentrations in equilibrium with atmospheric aerosols - experiment vs theory, Atmos. Environ., 18, 17371750, 1984.

Hudson, J. G. and Da, X. Y.: Volatility and size of cloud condensation nuclei, J. Geophys. Res., 101, 4435-4442, 1996.

Hutchinson, G. L., Mosier, A. R., and Andre, C. E.: Ammonia and amine emissions from a large cattle feedlot, J. Environ. Qual., 11, 288-293, 1982.

Khlystov, A., Stanier, C. O., Takahama, S., and Pandis, S. N.: Water content of ambient aerosol during the Pittsburgh air quality study, J. Geophys. Res., 110, D07S10, doi:10.1029/2004JD004651, 2005.

Kleeman, M. J., Hughes, L. S., Allen, J. O., and Cass, G. R.: Source contributions to the size and composition distribution of atmospheric particles: Southern California in September 1996, Environ. Sci. Technol., 33, 4331-4341, 1999.

Kreidenweis, S. M., Koehler, K., DeMott, P. J., Prenni, A. J., Carrico, C., and Ervens, B.: Water activity and activation diameters from hygroscopicity data - Part I: Theory and application to inorganic salts, Atmos. Chem. Phys., 5, 1357-1370, 2005, http://www.atmos-chem-phys.net/5/1357/2005/.

Kumar, P. P., Broekhuizen, K., and Abbatt, J. P. D.: Organic acids as cloud condensation nuclei: Laboratory studies of highly soluble and insoluble species, Atmos. Chem. Phys., 3, 509-520, 2003, http://www.atmos-chem-phys.net/3/509/2003/.

Lance, S., Medina, J., Smith, J. N., and Nenes, A.: Mapping the operation of the DMT Continuous Flow CCN counter, Aerosol Sci. Tech., 40, 242-254, 2006.

Lobert, J. M., Scharffe, D. H., Hao, W. M., Kuhlbusch, T. A., Warneck, P., and Crutzen, P. J.: Experimental evaluation of biomass burning emissions: Nitrogen and carbon containing compounds, in: Global Biomass Burning: Atmospheric, Climate and Biospheric Implications, edited by: Levine, J. S., MIT Press, Cambridge, MA, 1991.

Makela, J. M., Yli-Koivisto, S., Hiltunen, V., Seidl, W., Swietlicki, E., Teinila, K., Sillanpaa, M., Koponen, I. K., Paatero, J., Rosman, K., and Hameri, K.: Chemical composition of aerosol during particle formation events in boreal forest, Tellus B, 53, 380393, 2001.

Manahan, S. E.: Environmental Chemistry, Eighth Edition, CRC Press, Boca Raton, Florida, 2005.

Maria, S. F., Russell, L. M., Turpin, B. J., Porcja, R. J., Campos, T. L., Weber, R. J., and Huebert, B. J.: Source signatures of carbon monoxide and organic functional groups in Asian Pacific Regional Aerosol Characterization Experiment (ACEAsia) submicron aerosol types, J. Geophys. Res., 108, 8637, doi:10.1029/2003JD003703, 2003. 
McLafferty, F. W. and Turecek, F.: Interpretation of Mass Spectra, Fourth Edition, University Science Books, Mill Valley, California, 1993.

Meng, Z. Y. and Seinfeld, J. H.: Time scales to achieve atmospheric gas-aerosol equilibrium for volatile species, Atmos Environ., 30, 2889-2900, 1996.

Milne, P. J. and Zika, R. G.: Amino-acid nitrogen in atmospheric aerosols - occurrence, sources and photochemical modification, J. Atmos. Chem., 16, 361-398, 1993.

Mochida, M., Kuwata, M., Miyakawa, T., Takegawa, N., Kawamura, K., and Kondo, Y.: Relationship between hygroscopicity and cloud condensation nuclei activity for urban aerosols in Tokyo, J. Geophys. Res., 111, D23204, doi:10.1029/2005JD006980, 2006.

Moore, R. H., Ingall, E. D., Sorooshian, A., and Nenes, A.: Molar mass, surface tension, and droplet growth kinetics of marine organics from measurements of CCN activity, Geophys. Res. Lett., 35, L07801, doi:10.1029/2008GL033350, 2008.

Mosier, A. R., Andre, C. E., and Viets, F. G.: Identification of Aliphatic-Amines Volatilized from Cattle Feedyard, Environ. Sci. Technol., 7, 642-644, 1973.

Mozurkewich, M.: The dissociation-constant of ammoniumnitrate and Its dependence on temperature, relative-humidity and particle-size, Atmos Environ., 27, 261-270, 1993.

Murphy, D. M. and Thomson, D. S.: Chemical composition of single aerosol particles at Idaho Hill: Positive ion measurements, J. Geophys. Res., 102, 6341-6352, 1997.

Murphy, S. M., Sorooshian, A., Kroll, J. H., Ng, N. L., Chhabra, P., Tong, C., Surratt, J. D., Knipping, E., Flagan, R. C., and Seinfeld, J. H.: Secondary aerosol formation from atmospheric reactions of aliphatic amines, Atmos. Chem. Phys., 7, 2313-2337, 2007, http://www.atmos-chem-phys.net/7/2313/2007/.

Nenes, A., Charlson, R. J., Facchini, M. C., Kulmala, M., Laaksonen, A., and Seinfeld, J. H.: Can chemical effects on cloud droplet number rival the first indirect effect?, Geophys. Res. Lett., 29, 1848, doi:10.1029/2002GL015295, 2002.

Neuman, J. A., Nowak, J. B., Brock, C. A., Trainer, M., Fehsenfeld, F. C., Holloway, J. S., Hubler, G., Hudson, P. K., Murphy, D. M., Nicks, D. K., Orsini, D., Parrish, D. D., Ryerson, T. B., Sueper, D. T., Sullivan, A., and Weber, R.: Variability in ammonium nitrate formation and nitric acid depletion with altitude and location over California, J. Geophys. Res., 108, 4557, doi:10.1029/2003JD003616, 2003.

Ngwabie, N. M., Custer, T. G., Schade, G. W., Linke, S., and Hinz, T.: Mixing ratio measurements and flux estimates of volatile organic compounds (VOC) from a cowshed with conventional manure treatment indicate significant emissions to the atmosphere, Geophys. Res. Abstr., 7(01175), 2005.

Petters, M. D. and Kreidenweis, S. M.: A single parameter representation of hygroscopic growth and cloud condensation nucleus activity. Atmos. Chem. Phys., 7, 1961-1971, 2007, http://www.atmos-chem-phys.net/7/1961/2007/.

Prenni, A. J., De Mott, P. J., and Kreidenweis, S. M.: Water uptake of internally mixed particles containing ammonium sulfate and dicarboxylic acids, Atmos Environ., 37, 4243-4251, 2003.

Pun, B. K. and Seigneur, C.: Understanding particulate matter formation in the California San Joaquin Valley: conceptual model and data needs, Atmos. Environ., 33, 4865-4875, 1999.
Rabaud, N. E., Ebeler, S. E., Ashbaugh, L. L., and Flocchini, R. G.: Characterization and quantification of odorous and non-odorous volatile organic compounds near a commercial dairy in California, Atmos. Environ., 37, 933-940, 2003.

Rissler, J., Pagels, J., Swietlicki, E., Wierzbicka, A., Strand, M., Lillieblad, L., Sanati, M., and Bohgard, M.: Hygroscopic behavior of aerosol particles emitted from biomass fired grate boilers, Aerosol Sci. Tech., 39, 919-930, 2005.

Rissler, J., Vestin, A., Swietlicki, E., Fisch, G., Zhou, J., Artaxo, P., and Andreae, M. O.: Size distribution and hygroscopic properties of aerosol particles from dry-season biomass burning in Amazonia, Atmos. Chem. Phys., 6, 471-491, 2006, http://www.atmos-chem-phys.net/6/471/2006/.

Roberts, G. C. and Nenes, A.: A continuous-flow streamwise thermal-gradient $\mathrm{CCN}$ chamber for atmospheric measurements, Aerosol Sci. Tech., 39, 206-221, 2005.

Rose, D., Gunthe, S. S., Mikhailov, E., Frank, G. P., Dusek, U., Andreae, M. O., and Poschl, U.: Calibration and measurement uncertainties of a continuous-flow cloud condensation nuclei counter (DMT-CCNC): CCN activation of ammonium sulfate and sodium chloride aerosol particles in theory and experiment, Atmos. Chem. Phys., 8, 1153-1179, 2008, http://www.atmos-chem-phys.net/8/1153/2008/.

Ruehl, C. R., Chuang, P. Y., and Nenes, A.: How quickly do cloud droplets form on atmospheric particles?, Atmos. Chem. Phys., 8, 1043-1055, 2008, http://www.atmos-chem-phys.net/8/1043/2008/.

Rumburg, B., Mount, G. H., Yonge, D., Lamb, B., Westberg, H., Filipy, J., Bays, J., Kincaid, R., and Johnson, K.: Atmospheric flux of ammonia from sprinkler application of dairy waste, Atmos Environ., 40, 7246-7258, 2006.

Russell, A. G., Mcrae, G. J., and Cass, G. R.: Mathematicalmodeling of the formation and transport of ammonium-nitrate aerosol, Atmos. Environ., 17, 949-964, 1983.

Schade, G. W. and Crutzen, P. J.: Emission of aliphatic-amines from animal husbandry and their reactions - potential source of $\mathrm{N} 2 \mathrm{O}$ and HCN, J. Atmos. Chem., 22, 319-346, 1995.

Seinfeld, J. H. and Pandis, S. N.: Atmospheric Chemistry and Physics, Second Edition, Wiley-Interscience, New York, 2006.

Shulman, M. L., Jacobson, M. C., Carlson, R. J., Synovec, R. E., and Young, T. E.: Dissolution behavior and surface tension effects of organic compounds in nucleating cloud droplets, Geophys. Res. Lett., 23, 277-280, 1996.

Sjogren, S., Gysel, M., Weingartner, E., Baltensperger, U., Cubison, M. J., Coe, H., Zardini, A. A., Marcolli, C., Krieger, U. K., and Peter, T.: Hygroscopic growth and water uptake kinetics of twophase aerosol particles consisting of ammonium sulfate, adipic and humic acid mixtures, J. Aerosol Sci., 38, 157-171, 2007.

Sorooshian, A., Brechtel, F. J., Ma, Y. L., Weber, R. J., Corless, A., Flagan, R. C., and Seinfeld, J. H.: Modeling and characterization of a particle-into-liquid sampler (PILS), Aerosol Sci. Tech., 40, 396-409, 2006a.

Sorooshian, A., Varutbangkul, V., Brechtel, F. J., Ervens, B., Feingold, G., Bahreini, R., Murphy, S. M., Holloway, J. S., Atlas, E. L., Buzorius, G., Jonsson, H., Flagan, R. C., and Seinfeld, J. H.: Oxalic acid in clear and cloudy atmospheres: Analysis of data from International Consortium for Atmospheric Research on Transport and Transformation 2004, J. Geophys. Res., 111, D23S45, doi:10.1029/2005JD006880, 2006b. 
Sorooshian, A., Ng, N. L., Chan, A. W. H., Feingold, G., Flagan, R. C., and Seinfeld, J. H.: Particulate organic acids and overall water-soluble aerosol composition measurements from the 2006 Gulf of Mexico Atmospheric Composition and Climate Study (GoMACCS), J. Geophys. Res., 112, D13201, doi:10.1029/2007JD008537, 2007a.

Sorooshian, A., Lu, M. L., Brechtel, F. J., Jonsson, H., Feingold, G., Flagan, R. C., and Seinfeld, J. H.: On the source of organic acid aerosol layers above clouds, Environ. Sci. Technol., 41, 46474654, 2007b.

Sorooshian, A., S. Hersey, F. J. Brechtel, A. Corless, R. C. Flagan, and Seinfeld, J. H.: Rapid, size-resolved aerosol hygroscopic growth measurements: differential aerosol sizing and hygroscopicity spectrometer probe (DASH-SP), Aerosol Sci. Tech., 42, 445-464, 2008.

Stelson, A. W., Friedlander, S. K., and Seinfeld, J. H.: Note on the equilibrium relationship between ammonia and nitric-acid and particulate ammonium-nitrate, Atmos. Environ., 13, 369-371, 1979.

Stelson, A. W. and Seinfeld, J. H.: Relative-humidity and temperature-dependence of the ammonium-nitrate dissociationconstant, Atmos. Environ., 16, 983-992, 1982a.

Stelson, A. W. and Seinfeld, J. H.: Relative-humidity and Phdependence of the vapor-pressure of ammonium-nitrate nitric acid-solutions at 25 degrees C, Atmos. Environ., 16, 993-1000, 1982b.

Stokes, R. H. and Robinson, R. A.: Interactions in aqueous nonelectrolyte solutions .I. Solute-solvent equilibria, J. Phys. Chem., 70, 2126-2130, 1966.

Svenningsson, I. B., Hansson, H. C., Wiedensohler, A., Ogren, J. A., Noone, K. J., and Hallberg, A.: Hygroscopic growth of aerosol-particles in the Po Valley, Tellus B, 44, 556-569, 1992.

Svenningsson, B., Rissler, J., Swietlicki, E., Mircea, M., Bilde, M., Facchini, M. C., Decesari, S., Fuzzi, S., Zhou, J., Monster, J., and Rosenorn, T.: Hygroscopic growth and critical supersaturations for mixed aerosol particles of inorganic and organic compounds of atmospheric relevance, Atmos. Chem. Phys., 6, 1937-1952, 2006 ,

http://www.atmos-chem-phys.net/6/1937/2006/.

Takahama, S., Wittig, A. E., Vayenas, D. V., Davidson, C. I., and Pandis, S. N.: Modeling the diurnal variation of nitrate during the Pittsburgh Air Quality Study, J. Geophys. Res., 109, D16S06, doi:10.1029/2003JD004149, 2004.

Tan, P. V., Evans, G. J., Tsai, J., Owega, S., Fila, M. S., and Malpica, O.: On-line analysis of urban particulate matter focusing on elevated wintertime aerosol concentrations, Environ. Sci. Technol., 36, 3512-3518, 2002.

Tang, I. N.: Chemical and size effects of hygroscopic aerosols on light scattering coefficients, J. Geophys. Res., 101, 19245$19250,1996$.

Taraniuk, I., Graber, E. R., Kostinski, A., and Rudich, Y.: Surfactant properties of atmospheric and model humiclike substances (HULIS), Geophys. Res. Lett., 34, L16807, doi:10.1029/2007GL029576, 2007.

Ulbrich, I. M., Lechner, M., and Jimenez, J. L.: AMS Spectral Database, http://cires.colorado.edu/jimenez-group/AMSsd/, 2008.

Ulbrich, I. M., Canagaratna, M. R., Zhang, Q., Worsnop, D. R., and Jimenez, J. L.: Interpretation of organic components from positive matrix factorization of aerosol mass spectrometric data, Atmos. Chem. Phys. Discuss., 8, 6729-6791, 2008, http://www.atmos-chem-phys-discuss.net/8/6729/2008/.

Vanneste, A., Duce, R. A., and Lee, C.: Methylamines in the marine atmosphere, Geophys. Res. Lett., 14, 711-714, 1987.

Varutbangkul, V., Brechtel, F. J., Bahreini, R., Ng, N. L., Keywood, M. D., Kroll, J. H., Flagan, R. C., Seinfeld, J. H., Lee, A., and Goldstein, A. H.: Hygroscopicity of secondary organic aerosols formed by oxidation of cycloalkenes, monoterpenes, sesquiterpenes, and related compounds, Atmos. Chem. Phys., 6, 23672388, 2006, http://www.atmos-chem-phys.net/6/2367/2006/.

Weast, R. C.: CRC Handbook of Chemistry and Physics, Sixty Eighth Edition, CRC Press, Florida, 1987.

Westerholm, R., Li, H., and Almen, J.: Estimation of aliphatic amine emissions in automobile exhausts, Chemosphere, 27, 1381-1384, 1993.

Wexler, A. S. and Seinfeld, J. H.: Analysis of aerosol ammoniumnitrate - departures from equilibrium during Scaqs, Atmos. Environ., 26, 579-591, 1992.

Wise, M. E., Surratt, J. D., Curtis, D. B., Shilling, J. E., and Tolbert, M. A.: Hygroscopic growth of ammonium sulfate/dicarboxylic acids, J. Geophys. Res., 108, 4638, doi:10.1029/2003JD003775, 2003.

Xiong, J. Q., Zhong, M. H., Fang, C. P., Chen, L. C., and Lippmann, M.: Influence of organic films on the hygroscopicity of ultrafine sulfuric acid aerosol, Environ. Sci. Technol., 32, 35363541, 1998.

Yu, S. C., Dennis, R., Roselle, S., Nenes, A., Walker, J., Eder, B., Schere, K., Swall, J., and Robarge, W.: An assessment of the ability of three-dimensional air quality models with current thermodynamic equilibrium models to predict aerosol NO3-, J. Geophys. Res., 110, D07S13, doi:10.1029/2004JD004718, 2005.

Zdanovskii, A.: New methods for calculating solubilities of electrolytes in multicomponent systems, Zh. Fiz. Khim.+, 22, 14751485, 1948.

Zhang, J., Chameides, W. L., Weber, R., Cass, G., Orsini, D., Edgerton, E., Jongejan, P., and Slanina, J.: An evaluation of the thermodynamic equilibrium assumption for fine particulate composition: Nitrate and ammonium during the 1999 Atlanta Supersite Experiment, J. Geophys. Res., 108, 8414, doi:10.1029/2001JD001592, 2002.

Zhang, X. Q., Turpin, B. J., McMurry, P. H., Hering, S. V., and Stolzenburg, M. R.: Mie theory evaluation of species contributions to 1990 wintertime visibility reduction in the GrandCanyon, J. Air Waste Manage., 44, 153-162, 1994.

Zhang, Q., Anastasio, C., and Jimenez-Cruz, M.: Watersoluble organic nitrogen in atmospheric fine particles (PM2.5) from northern California, J. Geophys. Res., 107, 4112, doi:10.1029/2001JD000870, 2002.

Zhang, Q. and Anastasio, C.: Free and combined amino compounds in atmospheric fine particles (PM2.5) and fog waters from Northern California, Atmos. Environ., 37, 2247-2258, 2003.

Zhang, Q., Alfarra, M. R., Worsnop, D. R., Allan, J. D., Coe, H., Canagaratna, M. R., and Jimenez, J. L.: Deconvolution and quantification of hydrocarbon-like and oxygenated organic aerosols based on aerosol mass spectrometry, Environ. Sci. Technol., 39, 4938-4952, 2005. 